BM.Ad.o.

\title{
INSTRUCTIONS FOR COLLECTORS
}

No. $2 \mathrm{~A}$

\section{BIRDS}

\section{TRUSTEES OF THE BRITISH MUSEUM (NATURAL HISTORY) LONDON: 1970}

Price: Four Shillings (20p.) 
L

B.M.

Ad. 


\title{
INSTRUCTIONS FOR COLLECTORS
}

No. $2 \mathrm{~A}$

\section{BIRDS}

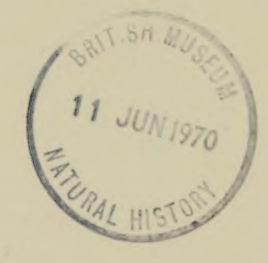

\author{
By \\ C. J. O. HARRISON \\ and
}

G. S. COWLES

illustrated by

A. L. DAHL 
(c) Trustees of the British Museum (Natural History) 1970

\section{Publication No. 561}

Standard Book No. 565005618 


\section{CONTENTS}

1. INTRODUCTION - -

2. TAKING SPECIMENS IN THE FIELD . . . . . . 6

Equipment . . . . . . . . . . . 6

Netting and trapping . . . . . . . 7

Killing wounded birds . . . . . . . 7

Noting data . . . . . . . . . . . 8

Preliminary care of specimens . . . . . . . 99

Collecting external parasites . . . . . . . . 9

3. PRePARING SKInS . . . . . . . . . 11

Instruments and materials for skinning . . . . . 11

Preparations for skinning . . . . . . . 11

Skinning instructions . . . . . . . . 12

Drying skins . . . . . . . . . 23

Large and long birds . . . . . . . . . 23

Alternative methods of skinning . . . . . . 25

Skull pneumatization . . . . . . . . . . 26

Sexing . . . . . . . . . . . 27

Crop and gut contents . . . . . . . . . . 29

Internal parasites . . . . . . . . . . 29

Packing skins for storage . . . . . . . 30

4. Preparing SKeletons . . . . . . . . . . . 31

Preparation . . . . . . . . . . . 31

Drying . . . . . . . . . . . 31

Wrapping . . . . . . . . . 32

Storage. . . . . 32

5. Preparing Whole SPECIMENS . . . . . . . . 33

Preparation . . . . . . . . . . 33

Packing. . . . . . . . . . . 34

6. Collecting eGgs . $\quad$. $\quad$. $\quad . \quad$. $\quad . \quad$. 35

Preservation . . . . . . . . . . . 35

Packing. . . . . . . . . . 36

7. Collecting NeSTS. . . . . . . . . 37

Collecting nest parasites . . . . . . . . 37

Preservation and packing of nests . . . . . . 37

8. RECORDING INFORMATION AND LABELLING . $\quad$. $\quad$. $\quad$ • $\quad$. 39

The information recorded . . . . . . 39

Recording information . . . . . . . . 40

Labelling . . . . . . . . 40

9. TRANSPORT . . . . . . . . . . . 42

APPENDIX 1. Chemicals and materials . . . . . . . 43

APPENDIX 2. Recommended publications . . . . . . 47

ACKNOWLEDGMENTS . . . . . . . . . . . . 48 



\section{INTRODUCTION}

Much information about birds has been gained through the study of preserved material assembled in museums. The parts of birds which are commonly preserved for comparative study are the SKIN, which is dried with legs, wings, and bill attached and is usually stuffed to resemble the live bird in shape; the SKELETON, as a series of loose bones kept together in a box rather than a single articulated structure; and the WHOLE SPECIMEN, which consists of the entire bird preserved in a fluid, formerly invariably alcohol, (hence the term "spirit specimens" which is sometimes used for such material). In addition both nests and eggs are collected.

All study collections require additional specimens of many species in one form or another. This is particularly true of birds from those parts of the world where travellers are infrequent, but may also apply elsewhere, and amateur naturalists and tourists may obtain specimens that prove of great value in research, while residents in remote areas are in the privileged position of being able to collect at all times of year and so supplement the information collected by sporadic visitors.

Since the random killing of birds and collecting of eggs and nests without definite scientific aim is very undesirable it is important to write to the museum and discover what material is wanted before starting to collect, although a collector in a remote region may have to rely on his own judgement. In most countries today there are laws for the protection of some or all birds, and in addition permits may be necessary to collect any species. Before collecting actually commences the collector must discover what legislation for bird protection exists in any area, and also obtain the necessary permits.

Although preparing a skin takes longer than other processes this is the traditional kind of bird specimen, and for this adults in fresh plumage tend to be selected. Skeletons are prepared more quickly as far as the time spent on them is concerned, but need more time to dry and may look and smell less pleasant, while whole specimens are quickly prepared but formerly offered difficulties of storage and transport. As a result skeletons and whole specimens, and the skins of juveniles and immature birds, and birds in moult, are usually needed more than adults in fresh plumage prepared as skins. 


\section{TAKING SPECIMENS IN THE FIELD}

\section{PERMITS}

Legislation varies considerably from one country to another, but permission and licences are usually required for the following:

1. Permission to collect specimens-obtained from the appropriate government. Such a permit may include stipulations as to the number of specimens to be taken, or forbid the collecting of certain species.

2. The appropriate gun licence or fire-arm certificate for each weapon. In this respect it should be remembered that any gun with a rifled barrel, even if it is only the 22 barrel of a combination collecting gun, is usually classed as a rifle and not a shotgun, and comes under more stringent regulations. It is especially liable to import and export restrictions. Collecting pistols, classed as short-barrelled shotguns, are also subject to stringent control.

3. Permission to collect-obtained from the owner of the property on which the specimens are taken.

4. Permission to export the collection (where appropriate). The granting of an initial collecting permit does not imply that the material may be exported, and the customs regulations should be ascertained when the collecting permit is obtained.

\section{EQUIPMENT}

(a). List. The following is a list of the basic equipment likely to be needed when collecting birds in the field.

Fieldglasses.

Gun.

Ammunition (preferably in a cartridge belt).

Haversack or rucksack.

Note-book or wallet of field-slips.

Tags or labels. (See section on "noting data".)

Pencil (and penknife) or waterproof pen.

Cotton wool.

Plastic bottle or tin with dusting powder.

Paper cones or wrapping material.

Additional equipment might include some form of humane killer (see below-killing wounded birds), and a small camera.

\section{(b). Notes on equipment}

Fieldglasses. These should be lightweight, with central focussing screw, and carried so that they do not obstruct the firing of the gun. A magnification of $\times 6$ to $\times 9$ is convenient for this purpose. A pamphlet on fieldglasses for use in bird study is published by the British Trust for Ornithology (Appendix 2).

Guns. A 410 shotgun is a convenient light weapon suitable for collecting a wide range of birds. With small birds in thick vegetation a $\cdot 22$ shotgun is useful, and the collector may prefer a combination of $\cdot 410$ and smoothbored 22 barrels. For greater distances and larger birds a 12 bore is to be 
preferred; and a 12 bore with an adaptor for .410 ammunition is another useful combination.

Ammunition. Very fine shot such as dust shot, which makes tiny perforations but does no major damage to the specimen, should be used. Dust shot is obtainable from gunsmiths but is usually not in stock and requires a special order. Allowance should be made for possible delays in obtaining it. No. 6 shot should be used on birds larger than crows, and no. 4 for really large birds.

Haversack. This should be as capacious as possible and divided into compartments to keep the birds separate from hard objects. Rubber-lined haversacks should not be used in humid conditions since these speed decay.

Tags. There is little time to label specimens properly and it is more convenient to tie a numbered tag to the bird immediately it is shot and to enter this number against any data that are noted.

\section{NETTING AND TRAPPING}

As an alternative to shooting, birds may be caught in nets or traps. With the advent of extensive ringing of birds for migration studies various types of traps have been used, and a pamphlet on the subject is available from the British Trust for Ornithology (see appendix 2). In general, trapping is only useful as a collecting method if the collector intends to remain in one place for a long period. In some areas the local population will have their own traditional methods of bird catching. Narcotised baits are now being increasingly used by authorities for dealing with species regarded as pests. Such baits usually stupefy the birds or render them unconscious for a period, and where they are available they may be of use to the collector. Since their effect may vary according to species and size they should be used with caution if selective collecting is desirable.

Mist-nets are the most convenient form of trapping for use in the field. These are fine nets that are erected on vertical rods, and catch the birds that fly into them. They have the advantage that the specimens produced are undamaged by shot, they allow the selection of specimens and the release of unwanted birds, and they trap forest and swamp species which may otherwise skulk and elude the collector. They have the disadvantage that time is required for erection and taking down of the nets and they will easily catch in any vegetation and require careful and lengthy disentangling, they only catch certain species, and are of little use in windy or wet conditions. The rapid removal of birds from the net requires a certain degree of skill, and if a bird is required as a specimen it is usually easier to kill it in the net prior to removal (see below-"killing wounded birds"). A pamphlet on the use of mist-nets is available from the British Trust for Ornithology (see appendix 2).

\section{KILLING WOUNDED BIRDS}

A wounded bird must be caught and killed as soon as possible, both for humane reasons and to prevent further damage to it. Under no circumstances should it be struck on the head, nor should the neck be wrung, since both produce haemorrhages that complicate the subsequent preparation. Birds can be killed by a compression of the body which appears to retard lung, and hence heart, action, resulting in a rapid and merciful death within 
a few seconds. This may be done in several ways. The sides of the body in the areas just below and posterior to the shoulder joints may be compressed and this has a rapid result, especially when combined with pressure on the windpipe. Pressure on the breast bone, or on either side of the body just posterior to the breast bone, has a similar result. Small birds can easily be killed in this manner with one hand but in the case of really large birds it may be necessary to hold them down on the ground or kneel on them, and if the first method is used the wings should be raised above the back and pressure applied from behind. When birds which have been shot are killed by pressure they should be held with the head downwards, since if there are internal injuries pressure may cause loss of blood from the bill which may soil the plumage.

Care must be taken when approaching and handling wounded birds which can inflict injury. Owls and birds of prey fight defensively with their claws and are capable of striking rapidly, especially if lying on their backs. The legs should be firmly grasped to prevent this. It may be possible to kill a grounded bird of this type, or one capable of inflicting a nasty bite, by carefully applying pressure to the breast bone with one foot before picking the bird up. Herons and various other birds lunge viciously and usually aim particularly at the eyes and head. Birds with wing-spurs, such as plovers and screamers, should be handled with care.

There are some birds, kingfishers and rollers for instance, which are extremely difficult to kill by pressure. These, and the larger, more difficult birds, can be killed extremely rapidly by the injection of a substance which is at present used by veterinary practitioners to bring about rapid and painless death. This is a Pentobarbitone solution which is sold under a variety of names (see appendix 1). It is used by some field collectors but its usefulness is offset by the need to carry, load, and use a hypodermic syringe in the field. This might be overcome to some extent by using the type of syringe which takes pre-filled cartridges. Anaesthetics such as chloroform and ether can also be used, but tend to take longer to kill the birds and are also difficult to carry in the field.

\section{NoTING DATA}

As soon as the bird is killed it must be marked with a numbered tag or label and the essential data must be noted on the spot (see also section 8 for comprehensive information on labelling). Note the name of the locality, and the time and date of collection. The fugitive colours (the so-called "soft-part" colours) of legs and feet, bill, mouth lining, eyes, and any bare skin or wattles should be noted immediately, since some of them may fade or change extremely rapidly at death. If accurate weights are required they should be taken as soon as possible after death, particularly when collecting in hot dry climates.

The above are essential but if possible also note briefly the type of vegetation, the particular part of the habitat that the bird appeared to be occupying (especially in forest where birds may confine themselves to particular strata of the vegetation), the altitude, and other surrounding factors; the bird's behaviour, and whether or not it was associating with others. 


\section{PRELIMINARY CARE OF SPECIMENS}

The final appearance of the specimen may depend on the care which it receives when first picked up. It should be held by bill or feet, not by the tail. The plumage should be smoothed and examined for any blood or dirt. Blood and mud should be carefully wiped away with absorbent material such as cotton wool, cloth, or paper tissues, care being taken to avoid staining feathers. Any wound or hole, once wiped clean, should be liberally dusted with dusting powder which will help to dry it and clot the blood. A cotton wool plug should be used to cover it and prevent further drainage. Any dried blood on the feathers should be left until after the skinning. The throat should be plugged immediately to prevent drainage of stomach contents and juices, and in larger birds it may also be necessary to plug the nostrils and vent. If flesh-eating or fish-eating birds have the crop or gullet distended with food empty these parts as far as possible by squeezing the contents out through the mouth to avoid unduly rapid decomposition. If the eyes are punctured these should be pressed lightly, dusted with skinning powder, and then dried and covered with a piece of cotton wool.

The dead birds should be packed for carrying so that they cannot shake about loosely, nor suffer pressure. Large birds should be well wrapped in absorbent but thin material, or in sheets of paper, the plumage being smoothed first to avoid bent or ruffled feathers which are difficult to straighten later. Smaller birds may be placed in cones, prepared by rolling sheets of paper. The bird should be slid in beak first, care being taken that the head is not doubled back. Such cones can easily be packed point downwards in a haversack or bag, and empty cones can be packed one inside the other to occupy little space.

If the birds are likely to remain unprepared until the next day, or to be carried around for hours in humid weather, it may be necessary to treat them to delay the onset of decay. There is often a rapid deterioration of the skin resulting in the "slipping" of the feathers and of fine structures in the whole specimen before gross decay becomes evident. To prevent this the abdominal cavity should be injected with a hypodermic syringe, and the inside of the mouth and throat should be swabbed with a formalin-based solution (see appendix 1). This will arrest decay, and such specimens can be skinned at a much later time than with ordinary specimens. Formalin should not be used on specimens which are to be made into skeletons, but alcohol can be used instead. As far as possible flies should be prevented from laying eggs or larvae on the freshly dead birds since in hot climates this may mean that maggots are already at work by the time that skinning commences. Maggots may be killed by swabbing the affected part with formalin or alcohol. In the Ornithologists' Guide (1956) a technique is described for preserving small birds in the field for subsequent skinning by using salt. This has been found to discolour plumage, soften the bill, and destroy inscriptions on labels and should not be used.

\section{COLlecting EXTERNAL PARASITES}

Bird collectors may make important contributions to the study of avian parasitology, and external parasites should be collected if circumstances 
allow. Brief information on this is given below and more detailed instructions are available in a publication of the Smithsonian Institution (see appendix 2).

Birds have a wide range of external parasites including louse-flies, fleas feather lice, chewing lice, mites, and ticks, and ranging from the conspicuous to the minute. In collecting many of these it is vital that there should be an exact determination of the host on which they were found. This is especially necessary in the case of feather-lice and chewing lice which tend to be associated with particular host species. If several birds are collected at one time and placed or carried in close proximity to each other some parasites may rapidly transfer themselves from one host to another. It is therefore essential that each specimen to be examined is carefully and individually wrapped, and it may be advisable to confine the collection of external parasites to specimens collected singly. It is also necessary to clean with scrupulous care all bags, wrappings, and surfaces on which parasites have been shaken out, or to which they may have been transferred, before using them again.

To collect the parasites the dead bird should be placed in a bag of linen or butter-muslin immediately after death to prevent the escape of fleas or louseflies. The bag is then placed in an air-tight box for about half-an-hour together with a piece of cotton wool soaked in chloroform. This will kill or stupefy the ectoparasites and the bird can then be shaken over any smooth white surface such as paper or a plastic table cloth. The feathers should be ruffled, especially under the wings, and the head knocked on the table to dislodge the head lice. The quills of the wing feathers should be examined for small holes denoting the presence of lice or mites within; the gular pouch of members of the Pelecaniformes should also be examined for lice. Parasites can also be collected from the wrappings of bags if the birds have been kept in these for some time, and when birds are heavily parasitised some parasites can be picked directly off them.

The parasites should be picked up with fine forceps or from a smooth surface with a fine brush or needle dipped in alcohol. They should be placed in tubes of $80 \%$ alcohol (gin or whisky can be used in an emergency) but never in formalin or any preservative containing formalin, and never with cotton wool in the tube. The name and collector's number of the host species, its sex and age, and the locality and date should all be entered on a slip of paper in the tube, and the latter should be firmly corked or sealed to prevent loss of moisture. (See also the section on collecting nests for external parasites found in nests.) 


\section{PREPARING SKINS}

Preparing a skin is the longest and most complex form of preparation of a bird as museum material. The following account describes the method most frequently used and some variations which have also proved successful.

\section{INSTRUMENTS AND MATERIALS FOR SKINNING}

Although birds have been skinned with only a penknife, the more adequate the equipment the easier and speedier the skinning will be, and the more satisfactory the final product. For competent general collecting the following equipment is suggested, the first list being the essential mirimum and the second the useful additional items.

1 pair fine pointed scissors with blades about 1 inch long.

1 scalpel with blade about $1 \frac{1}{2}$ inches long.

1 small surgeon's scalpel with detachable blades.

1 pair medium forceps about 5 inches overall.

$1 \frac{1}{2}$ inch stiff flat paint brush, for applying preservative.

Sewing and darning needles, assorted sizes.

Reels of sewing cotton and thread.

Absorbent cotton wool.

Dusting powder (see appendix 1).

Insect repellant (see appendix 1).

Preservative for skins (see appendix 1).

Collector's labels.

Note book, pens, ink, etc.

Useful additions to the above are;

1 pair medium sized pointed scissors with blades about $1 \frac{1}{2}-1 \frac{3}{4}$ inches long.

1 pair large round-tipped forceps about 10 inches overall.

1 pair side-cutting pliers for wire and bone.

1 artist's paint brush, soft hair no. 6 .

1 carborundum stone for sharpening scalpels.

1 pair of dividers.

1 rustless steel rule divided into millimetres.

Pins.

Wooden sticks and split cane (see appendix 1).

Tow or wood wool ("excelsior").

Powdered Alum.

Small coil of galvanised wire.

Paper (newspaper).

Hand-lens.

\section{PREPARATIONS FOR SKINNING}

Working under field conditions is difficult and where possible a table or flat board should be used as a working surface. Sheets of newspaper which can be changed when soiled can be used to cover the surface. The skinning tools and material should be set out on the working area in a consistent and convenient arrangement, together with a small pot of water. To ensure cleanliness of plumage while skinning it is essential to use only one side or 
corner of the table for discarded flesh and brains. A repellent fly-spray is useful.

Fresh blood stains can be removed from the plumage after the bird has been skinned. Dry blood clots can be brushed away with a small stiff brush and the stains removed by repeated applications of cold water and a little soap on a swab of cotton wool, renewing the swab frequently. Dry the plumage by mopping with absorbent cotton wool and then applying liberal amounts of absorbent dusting powder until the plumage is quite dry and fluffed out. Small birds with extensively wetted plumage may be dried more easily by gently shaking them with dusting powder in a closed container.

Shortly after death rigor mortis occurs, the wings, legs, and neck of the specimen becoming rigid for a period. To ease such stiffness prior to skinning, the limbs should be gently and firmly worked to and fro at the joints until they feel relaxed and flexible. Care must be taken when manipulating small birds, since the leg bones break easily.

It is often an advantage when skinning birds with small beaks first to pass a short length of sewing thread through its nostrils and then to tie the ends to form a loose loop which can be used later to draw the skull back through the neck after cleaning it.

\section{SKINNING}

1. First incision (fig. 1). Place bird on flat surface covered with clean paper, belly up and bill to your left (if right-handed). Part breast feathers

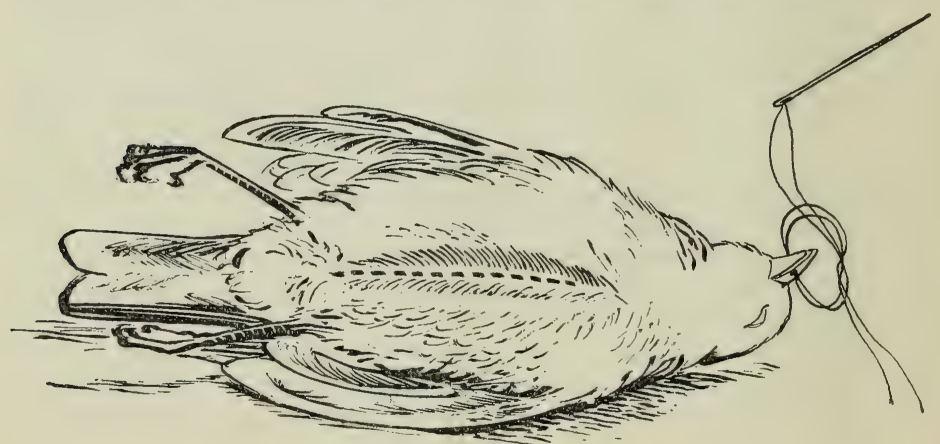

FIG. 1.

with fingers to expose bare skin along mid-line of body. Cut along skin down middle of body from mid-breast to vent, using scalpel or pulling up small fold of skin with forceps and cutting skin with scissors. The latter method avoids deep cuts, especially over the thin belly wall.

2. Detaching skin. Hold skin with fingers or forceps, using fingertips and nails or scalpel handle to ease it away from flesh. Keep flesh and skin of bird, and fingers, dry with dusting powder constantly applied. If blood or fluid escapes plug holes with cotton wool and dredge with dusting powder. Ignore very small holes or splits in skin. Large ones should be left until skin is well clear of body, then sewn up from inside. 
3. Skinning breast and belly. Ease away skin equally on each side of incision, working back towards tail until concealed knees appear, close to body.

4. Detaching legs. Take hold of leg outside and push firmly inwards to body and upwards until accessible from inside skin. When knee is clear of skin cut right through at joint with stout scissors (or pliers for large birds), (fig. 2) severing leg from body. Repeat for other leg.

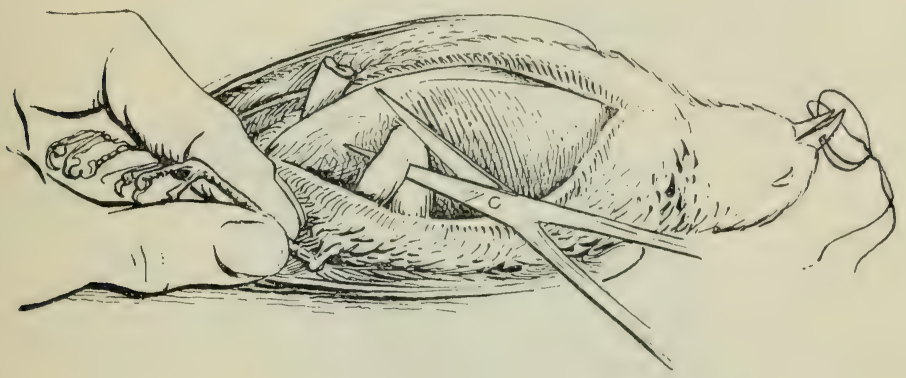

FIG. 2.

5. Detaching the tail. Continue skinning down and around pelvis until the base of the tail is reached. Lay bird on back with tail towards you (fig. 3), supporting body by forefinger of free hand pressing up under rump, and

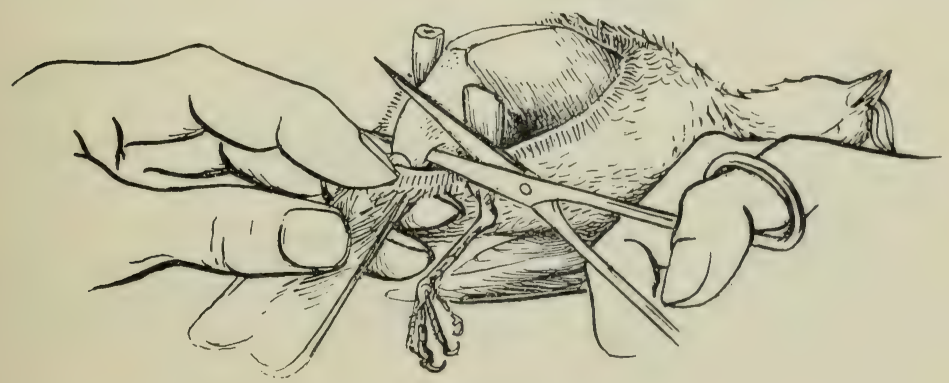

FIG. 3.

thumb pressing down and back on tail to stretch abdomen and make tailstump visible. With scissors cut carefully through body and vertebrae just above base of tail to free it from body, sliding lower blade between body and skin of rump. Finger under rump should feel if skin is penetrated. Cutting too near tail will cut the base of tail quills causing feathers to fall out, cutting too far from tail will open body cavity. 
6. Skinning back. With tail completely freed, grip severed backbone with forceps, raise body, and continue to strip skin carefully away from back, working towards head (fig. 4). When pelvis is exposed body can be held in fingers or for very large birds suspended by a hook or string. Fingers can be

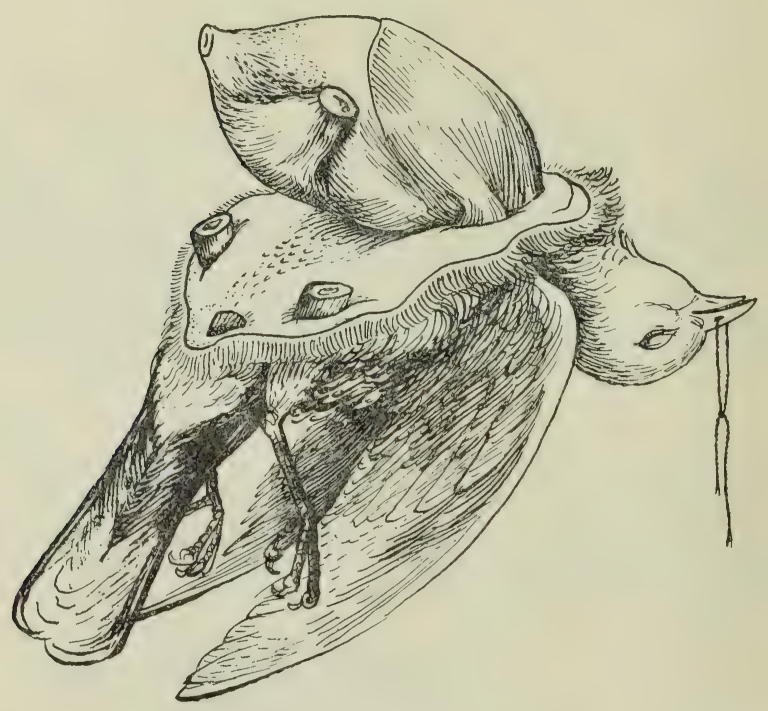

FIG. 4.

used, but stubborn muscle slips adhering to skin may require cautious use of scalpel. As skinning progresses towards shoulders the skin should be turned inside out to protect plumage.

7. Detaching wings. Continue skinning until shoulder joints are visible. To detach the wings the humerus bone may be cut through near the shoulder with heavy scissors (fig. 5), especially in small birds, but with practice the shoulder joint may be disarticulated with a scalpel without splintering the bone. Detach both wings.

8. Skinning head. The skin is now inside out and joined only to head and neck. Gently peel back skin along neck until back of skull comes into view.

Some birds, such as woodpeckers and ducks, have skulls which are too large to pass through the neck of a skin. If it is not possible to continue peeling the skin over the head to expose the entire posterior half of the skull without tearing the skin it is then necessary to cut off the neck near the base of the skull, leaving enough to use a grip, and then to make an incision in the skin from hind-crown to nape. The remains of neck and back of the head 


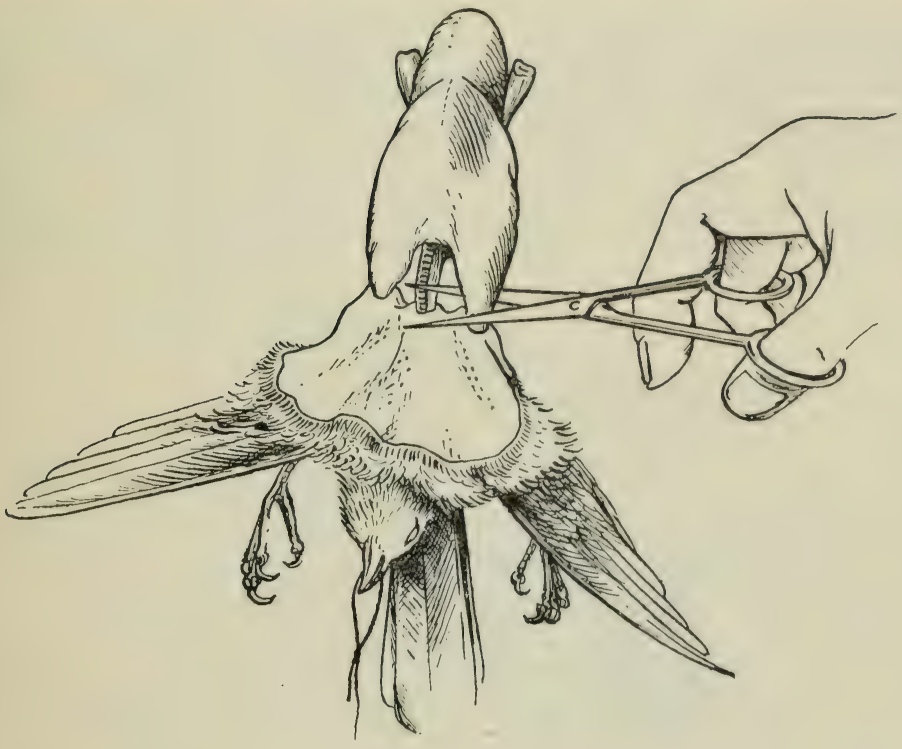

FIG. 5.

are accessible through this incision, the skin on each side being turned back (fig. 6). The skull is cleaned and skin reversed in the normal way and the slit sewn up. With hornbills, guinea-fowl and other birds with casques or
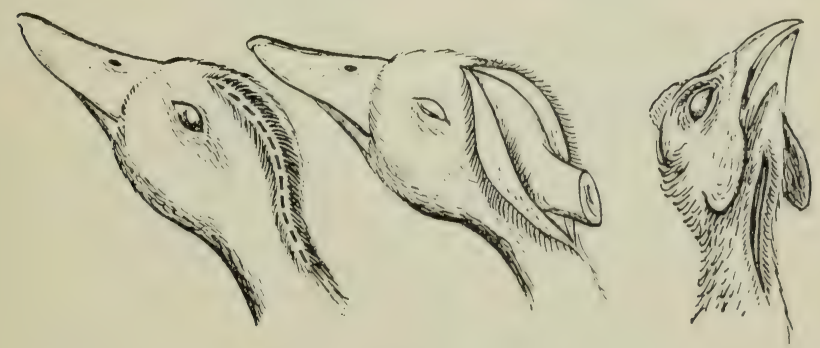

Fig. 6.

special head ornamentation the process is similar except that the slit is made in the throat.

Ease skin carefully over skull and do not pull skin of neck to do so. Continue until rear of cranium is exposed and skin held by strip to ears on either side.

9. Ears and eyes. The skin lines the ear-cavities and these "ear-pockets" will be visible as narrow strips extending back into the ear. Slip one tip of 
fine forceps under this strip near the ear-cavity, grip, and pull out (fig. 7a). Do not cut through with scissors or a hole will result. Now separate head from body by cutting through neck close to skull. Place body on one side for later sexing (p. 27). Continue peeling skin forwards over head to reveal rear half of each eye. Break the thin membrane between the eye and edge of orbit with point of forceps, and by reaching deeper behind eye break the few small muscle bands. Now reach behind eye, deep into socket, and close forceps on large optic nerve connecting eye to brain (fig. 7b). Pull upwards

(a)
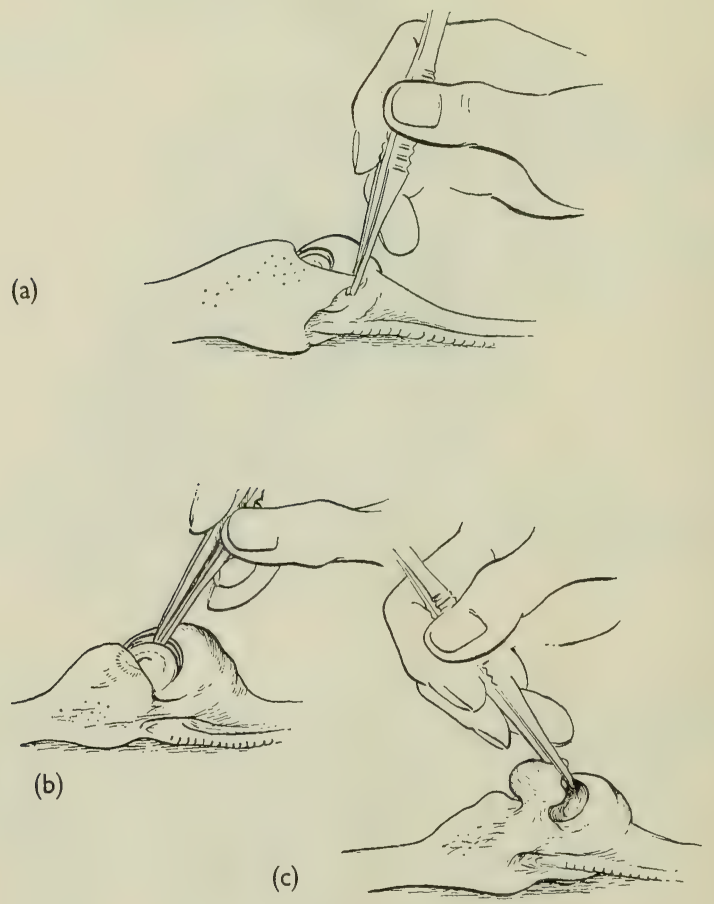

FIG. 7.

and backwards to break nerve and lift undamaged eye clear of socket; leaving it still connected by thin membranes to eyelids of skin (fig. 7c). Cut these membranes, taking care not to cut eyelids or puncture eye. Should eye be punctured before or during skinning make sure any liquid is swabbed away and not allowed to wet skin or feathers.

Owls have a large bony ring round each eye. The rings should be removed, cleaned and replaced. Alternatively the eye can be punctured and drained but there is a danger that plumage may be soiled. Retaining the bony ring is important to give the characteristic owl features. 
10. Removing brain. Cut a square hole in back of cranium by inserting the points of open scissors through the thin bone and closing them, repeating this to cut out and remove a square of bone (fig. 8a). Break through the thin bone of the hind orbit that separates eyes and brain with the point of the

(a)

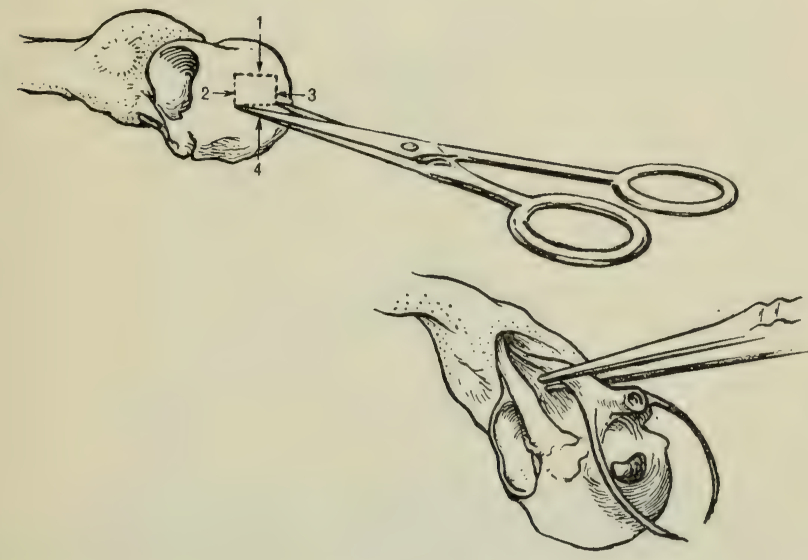

FIG. 8.

scissors. Force small pieces of cotton wool into the hole in the back of the skull, forcing the brain matter into the orbit and cleaning it away from there. When most of the brain is out remove any membraneous material with forceps through the square hole.

At this point the skull must be examined and the state of pneumatization noted (see p. 26).

11. Removing tongue and cleaning skull. Cut along the inside edge of the lower jaw on either side and pull away the tongue with forceps (fig. 8b). Where possible the tongue should be preserved for study. Tie on a tag with collector's number, species and sex written clearly in pencil, and place tongue and tag in a specimen tube of alcohol or a formalin solution (see appendix 1). Remove cotton wool plug in throat of bird. Scrape away flesh from skull, especially in birds such as parrots where jaw-muscles are quite massive. Take care not to disturb the joint between upper and lower jaw.

12. Replacing skin on head. Pack out orbits with cotton wool to replace eye. If skin has become dry apply a little water to keep it pliable, otherwise the next stage may damage it. Apply preservative to the skin of head and neck, and to skull. Carefully ease skin back over head, pushing skull back inside it and using only fingers and thumbs (fig. 9). The loop of thread through the nostrils can be used to turn head and neck right way out, but do not pull hard. Once the head is through, eyelids should be eased into the right position with forceps and the skin of face and throat smoothed into place. Disarranged feathers can be sleeked by inserting the eye of a large 


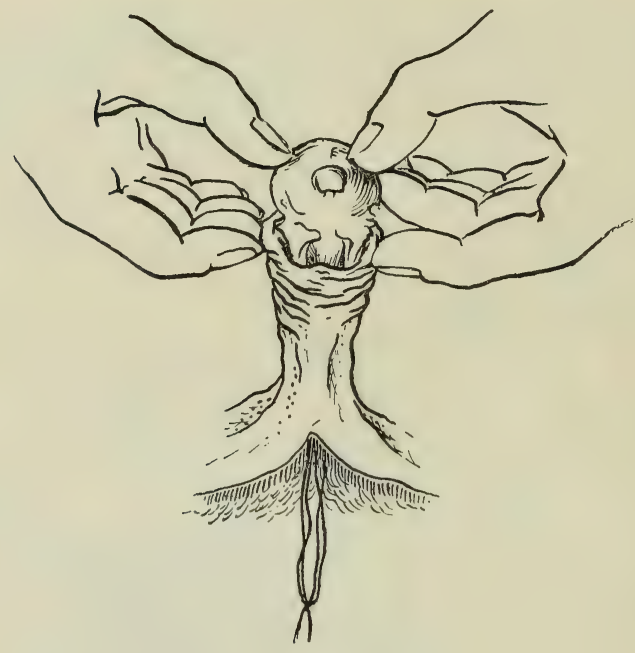

FIG. 9.

needle through the eye hole and moving it to and fro so that it rubs along the inside of the skin of the head, bringing the feathers back to a more natural position (fig. 10).

13. Cleaning wings. Peel skin downwards on wing to expose the upper arm bone and first joint. The skin can be pushed back to expose the upper

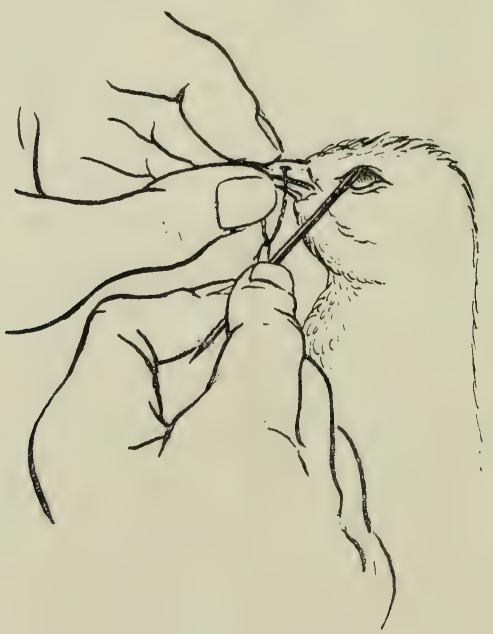

FIG. 10. 
part of the fore-arm below this joint, but the secondaries are attached to the lower part of it and these must not be moved (fig. 11). Remove flesh from around the upper arm bone and from between the paired bones of the forearm, as far as is possible. Rub alum into any flesh that cannot be removed. When clean wrap upper arm bone tightly with cotton wool to replace flesh removed.

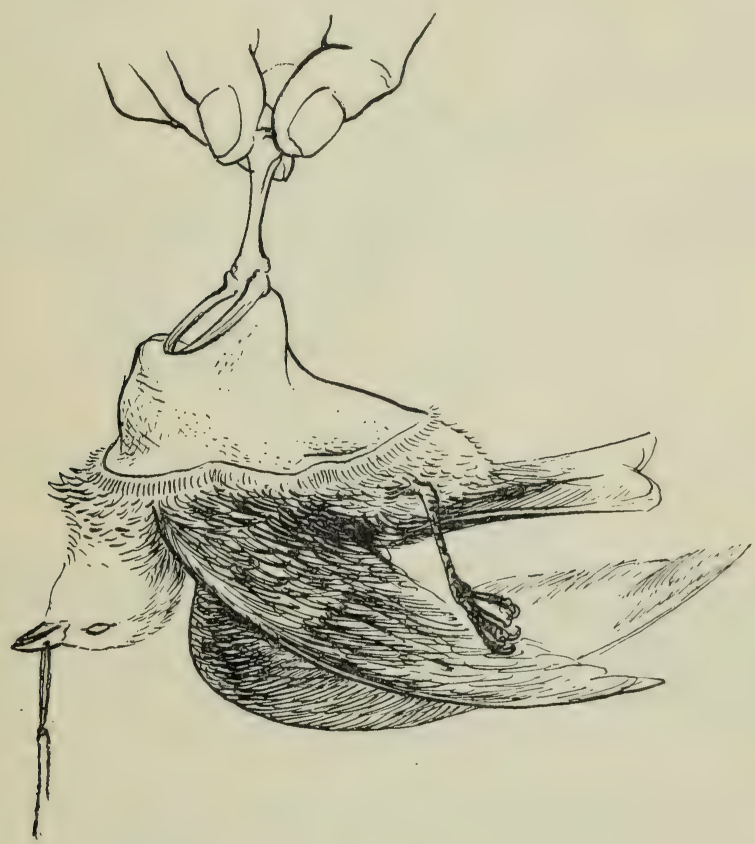

FIG. 11.

With larger birds such as ducks and hawks the muscles between the paired bones of the fore-arm can be reached from the underside of the wing by lifting the layer of small covert feathers along the edge to expose bare skin, cutting a slit in the skin through which the muscles can be reached and removed (fig. 12) and either sewing the slit again or, since it is held in place by the bones and covered by the feathers, leaving it open.

14. Cleaning legs. Peel skin down legs as far as the scaly leg cover which will not peel. Remove any muscle from the bones. Wrap the clean bone in cotton wool to replace the removed flesh.

15. Cleaning tail stump. Clean tail stump as far as possible but do not disturb the roots of the tail quills. Check for the presence of preen glands, which may appear as rounded white bodies situated on top of the tail stump. They are particularly large in ducks. They contain oil or fat and must be removed or destroyed. If they cannot be removed entirely, cut away as 


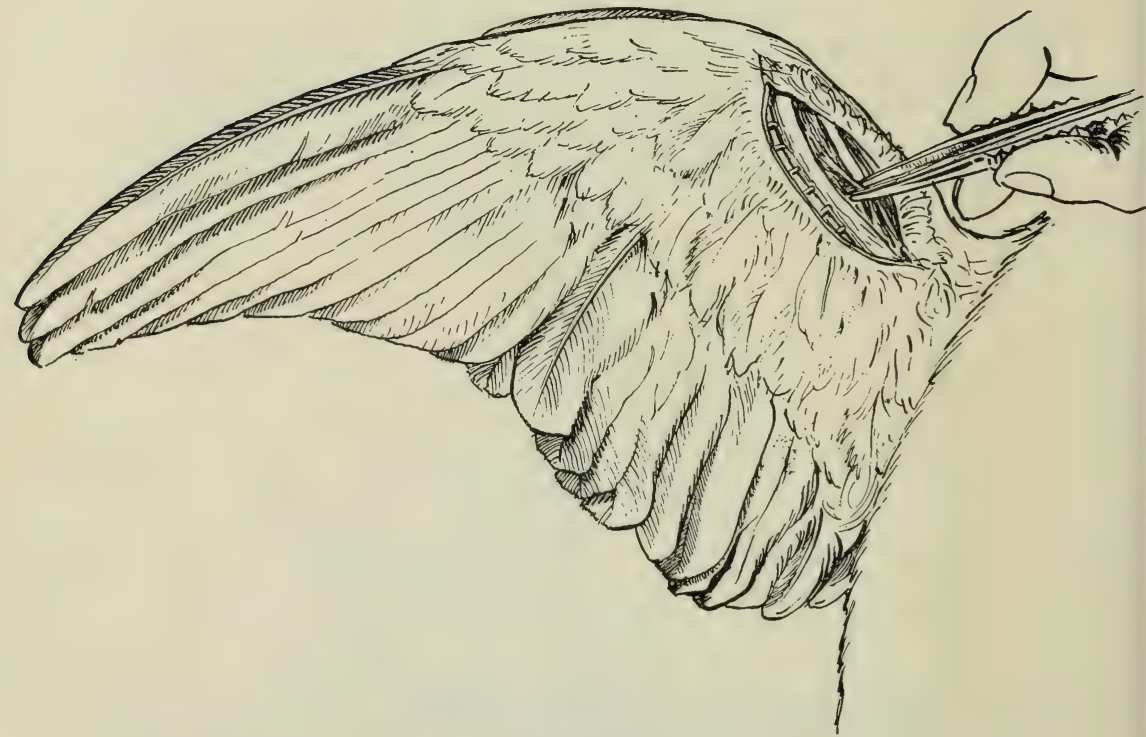

FIG. 12.

much as possible and then repeatedly apply and scrape off generous dustings of powder to remove any fat, breaking down the remains of the glands.

16. Tying scapulars. The skin is pulled into folds at the shoulders in the living bird but stretches in skinning. On the inside of the skin between the wings two parallel tracts of feathers bases can be seen. Take a needle and thread, pass it through these two tracts from inside the skin, (fig. 13) make a

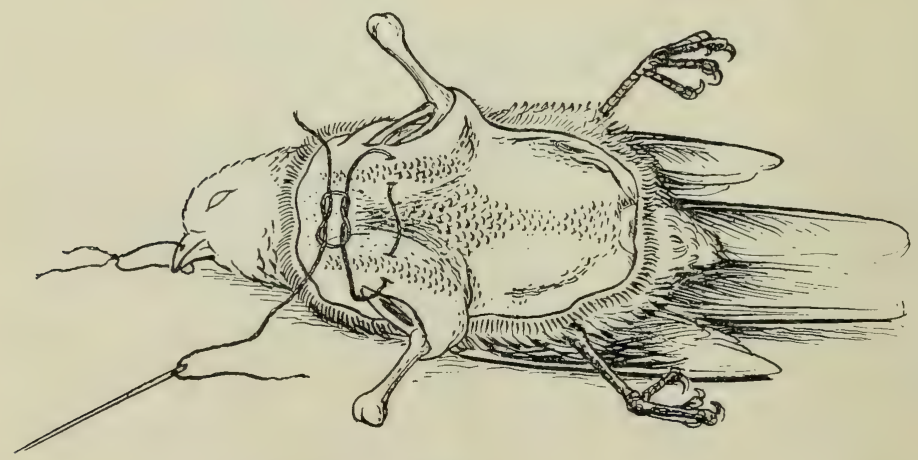

FIG. 13.

loop by knotting it to pull the two tracts together to a similar distance to that in the living bird. 
17. Removing fat. Remove any fat layers and any remaining flesh left attached to skin. At certain times of year many birds develop fat layers under the skin and to remove these scrape repeatedly, applying frequent dustings of powder to soak up the fat, and making sure that the tissues holding the fat are broken down. The back of a scalpel blade is useful for such scraping.

Ducks may have fat layers up to a quarter of an inch thick, with the feather bases embedded in them, and if the skin is not to become useless in later years this must be removed. Again continual scraping and dusting is necessary and a small wire brush is very useful in helping to break down the tissues holding the fat.

18. Removing leg tendons. In order to prevent later decay the leg tendons should be removed from the larger birds, and large-footed birds such as water birds and raptors. A deep cut is made in the sole of each foot, the points of strong forceps or a probe inserted under the exposed tendon (fig. 14)

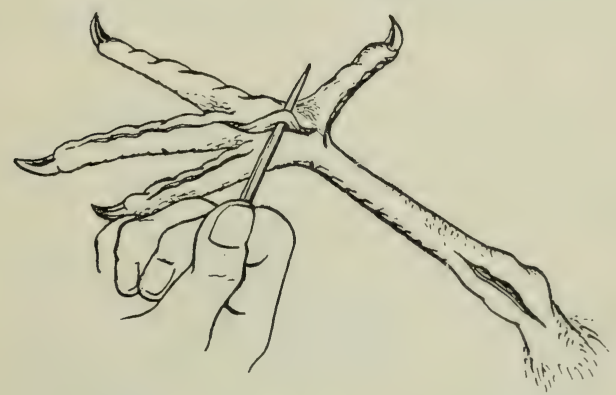

FiG. 14.

and the tendon levered firmly to extract the ends severed while cleaning the upper leg bones. The tendon can then be cut at the lower end and the tendon canal packed with preservative. Tendons should also be removed from beneath the toes of birds with large fleshy feet, and with such birds a slit should also be made in the joint of the leg so that a preservative can be inserted.

19. Applying preservative and preparing for stuffing. Apply preservative thoroughly to all the inner surfaces of the skin. If the skin has dried out in places moisten with water so that it is pliable before applying preservative. Turn legs and wings the right way out, carefully easing the skin over the thighs and opening the wings and folding them away in their natural position. The body is now ready for stuffing.

At this point it is advisable to clean the table or surface on which skinning is taking place, discarding fragments of flesh and tissues which might soil the finished skin, and placing the body carefully on one side for sexing (see p. 27).

At this stage, if it is impossible to stuff immediately, the skin can be left for a short period, overnight for example, provided that it is not allowed to dry out. This can be overcome by putting a cotton wool pad moistened with 
water inside the skin which is then placed in a box or polythene bag. This should be done after the preservative is applied.

20. Stuffing and sewing skin. Select a rigid but thin stick that will reach at least from eye to tail-tip of the specimen, and sharpen to a point. Bind for about two-thirds of the length from the sharp end with cotton wool, leaving the point exposed, and insert the point into base of skull, pushing well in until it can be felt just under crown feathers. Lay bird on back. Make sure neck is not unduly stretched and that legs and wings are right way round. Upper arm bones should be positioned as in life with ends pointing towards neck. Pack out neck and body with small pieces of cotton wool, symmetrically on each side of stick. Keep the stick central to form a back-bone with lower end protruding close to vent. Keep neck short. The skin of the neck tends to shrink and a plug of cotton wool in the throat gives a fuller appearance. Extra material can be inserted through mouth.

Take needle and thread, knot end of thread to stop it slipping, and stitch up incision working from breast to tail. Sew in zig-zag fashion, inserting needle from inside of skin outwards, placing stitches near edges of incision but not so close that they tear loose (fig. 15). Take care that feathers do not become

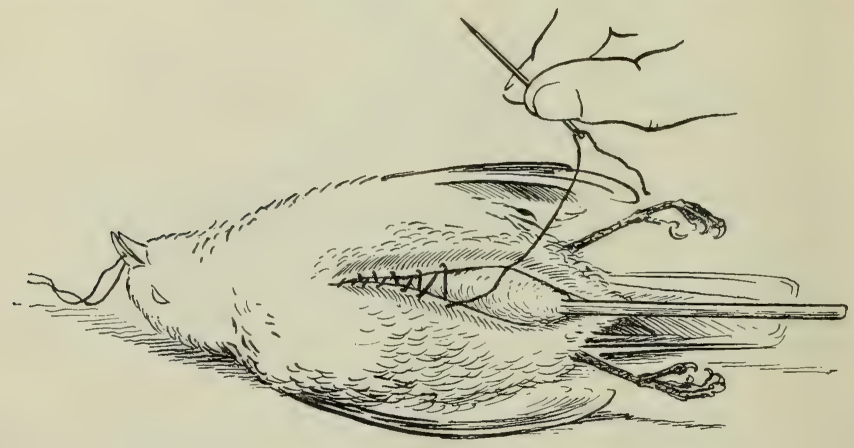

FIG. 15.

caught around the thread or trapped in the incision since these become twisted and spoil the final appearance of the specimen. The edges of the incision should be pulled together as stitching proceeds. Insert additional packing material as necessary to ensure that the finished specimen will have a firm body. The body removed during skinning gives an indication of the amount of material required. Take the final stitch round the stick close to the vent and then knot.

Place the legs over the stick, slightly bent at the joints and crossed halfway down the tarsus, so that the feet are clear of each other, and legs and feet can be examined and measured easily, then tie legs to stick. Cut loop of thread through nostrils, cross the ends round the lower mandible and tie the bill shut, cutting off loose ends. The field label can be tied on now, to the leg but not to the stick. Take care that subsequent data on sexing are added to it (see section on labelling, p. 39). Fold wings in natural 
position and straighten and smooth feathers with forceps until satisfied with appearance of specimen.

Beginners show a tendency to stretch the skin when stuffing, and it may be necessary to compress the specimen and ease the skin over in places to increase the overlap of feathers and give a better final result.

21. Wrapping for drying. The finished specimen needs to dry off while held in the correct position. For this purpose it should be placed in a paper tube (fig. 16). The tube is formed first, and the specimen then slid into it.

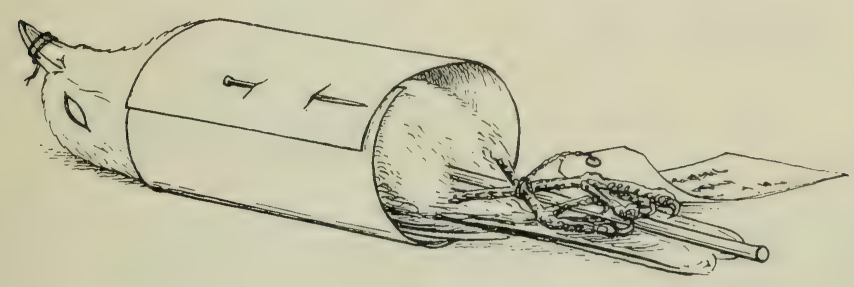

FIG. 16.

Take care that the position is the one finally required and that no feathers, particularly those of the crown of head, aud mantle, are disarranged. Leave the specimen in the tube, handling it by the protruding stick, until it is quite dry. (This stick is left until the specimen is added to a museum collection, when it is usually cut off close to the skin.)

22. Drying. This is a most essential part of the skinning process since it is the drying of the skin which principally preserves it, the preservative applied to it functioning mainly in preventing attack by insects or moulds. Skins require time to dry in freely circulating air, protected from animals and insects. Drying may take a week or more and in very moist atmospheres some additional arrangement may be required, such as gentle and prolonged heating.

The most convenient method for dealing with a number of skins is to use a crate with fine fly-wire sides and top and a solid bottom, and to have a series of wire-bottomed trays of varying depth which fit into this. The finished skins can be left to dry on the trays and the whole protected from bad weather by a cover. If the crate is to be transported with skins inside it will require a cover that excludes dust. For rough travelling a solid box or metal container into which the trays will fit is preferable. dry.

Skins may be tested for dryness by feeling the feet, which take longest to

23. Large and long birds.

(a) Large bodies. The skins of large birds present a problem because of the quantity of packing material required. If it is available in quantity they are best filled out with wood wool or tow. If this is not available the collector can use dry moss, grass, paper, or any available material that is light, dry, and insect-free.

(b) Long necks. Herons, flamingos, geese, and other long-necked birds should be made up with a wire in place of the usual stick. After skinning 
the bird, enough wood wool or alternative packing should be chosen to make an artificial body to the same size as the original bird body which has been removed earlier. Bind the packing material tightly with thin string to form a firm "mannikin". Select a length of galvanised wire which should be about six inches longer than the bird's neck when in the flesh, and strong enough to support the weight of the skull without bending too much. Insert about three inches of the wire into the end of the mannikin and if possible clench it tightly into place with pliers (fig. 17). Wrap the protruding

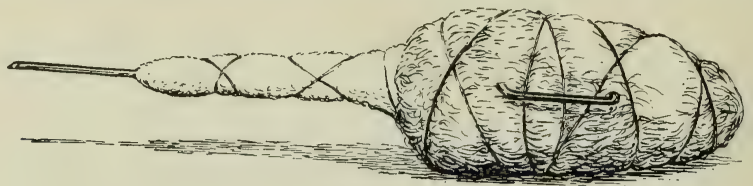

FIG. 17.

length of wire with tow or cotton wool to within three inches of the top end, using the original neck of the bird as a guide for diameter and length, and bind firmly with strong thread or string. Sharpen the bare wire to a point and insert the false neck and body mannikin into the skin. Force the wire point into the base of the skull and on through the brain cavity until it emerges through the plumage on the crown of the head. Slide the skull down the wire until it fits onto the end of the false neck and then bend the surplus few inches of wire under and over the bill. The wire can be cut off close to the skull when the skin is dry. With the body in position the neck can be bent to form an S-shape or doubled over the breast, and if necessary the bill can be turned to one side (fig. 18). This makes it possible to store and transport
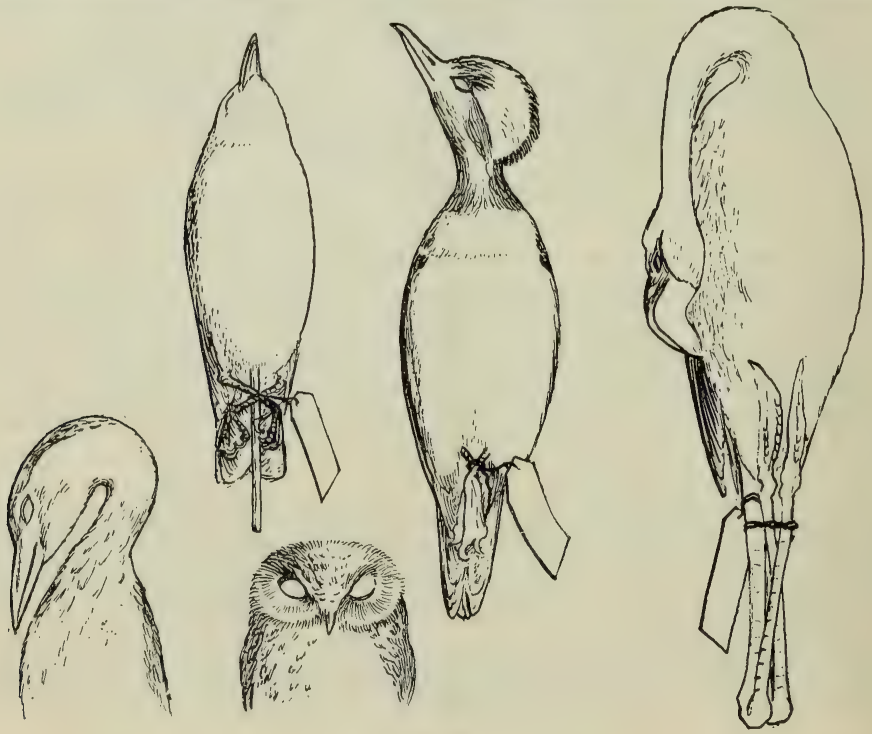

FIG. 18. 
long-necked birds more easily without risk of damage in transit. Before sewing up the skin in the usual way cotton wool should be packed around the mannikin body to fill out the skin shape in the usual manner. If wire is not available the neck should be packed with the normal packing material and folded over onto the breast.

(c) Long legs. Birds with exceptionally long legs can have these bent upwards over the breast and tied together (fig. 18). When this is done it is advisable to wrap the legs in paper to prevent damage to the breast plumage.

(d) Crests. Where species have elaborate erect crests it may be advisable to prepare a skin with the head turned to one side to prevent damage to the feathers (fig. 18).

\section{ALTERNATIVE METHODS OF SKINNING}

Although the methods described for skinning a bird is a proven one that achieves good results it is not the only method by which a skin can be made, the following methods can also be used.

1. Ventral incision with head and wings detached first. This has some advantages if the skin of the lower part of the body has become thin or fragile through damage or decay. In using this method the ventral incision should extend up to the mid-breast. The skin is first eased away from the breast and upper parts of the body, including the base of the neck, until it is possible to reach the wing-joint on one side; and this wing is then separated from the body. The skin is then eased over the shoulder and the neck severed at the base, head and neck being left in the skin for the moment. The other shoulder is then uncovered and the other wing severed. The skin can now be peeled down the body and carefully eased away from the difficult areas of the lower back and belly. It is also eased down along the leg to just below the knee joint. The leg can then be cut through or severed at the knee, leaving the skin attached by the tail only. It is then possible to clean the tail base region and separate the skin from the body by cutting through this region. The tail base is cleaned and the legs cleaned of flesh and wrapped in the usual way. The wing joints are cleaned and the neck and head are skinned back and cleaned in the normal way. The remainder of the preparation is the same as that of the first method described, but care must be taken in the final sewing-up to avoid undue disarrangement of the feathering on the underside resulting from the longer initial incision.

2. Lateral incision. This has the advantage that any pattern on the underside is not destroyed or disarranged by skinning, and the incision is concealed by the closed wing in the final skin. It has the disadvantage that it is difficult to insert the final stuffing symmetrically, and one wing tends to be displaced in the final skin. The incision is made near the wing-joint, just below the line of the humerus, downwards to the thigh. The skin is freed around the incision and there is easy access to one wing joint which is freed from the body. The skin is further loosened over the back and breast and eased over the shoulder to expose the base of the neck. The neck is severed and skinning continues to expose the other wing-joint. The bird is now skinned in a similar manner to that of the alternative method described above, the skin being freed down the body to the tail.

In stuffing the bird the wing on the side of the incision tends to be loosely 
attached and it is better to tie the two humeri together instead of pulling the dorsal feather tracts together with a loop of thread. This makes it difficult to insert a stick and several different methods of stuffing have been devised.

(A) This dispenses with the stick altogether. Most of the back of the skull is removed during cleaning. A smooth tapering stick such as a fine knitting needle, polished wooden spindle, or porcupine quill is taken and a body built up on this, to the same size as the bird's body, by twisting small lengths of cotton wool or tow around it, the shape tapering away towards the top. This body is inserted through the incision and up through the skull until the stick protrudes from the bill and the cotton wool tip is in the throat. The upper skin is arranged on the body while the stick is still in place and the skin and body are then held in one hand while the stick is rotated and withdrawn by the other, leaving one end of the cotton wool body protruding from the incision. There is enough flexibility in this for the end to be bent and inserted into the tail end of the skin, after which the body should regain its shape and hold the skin rigid. The incision is often simply left open but it is advisable to insert a few stitches to ensure that the wing is held in place. In this method there is always the danger that if the body is not well-made the resultant skin will be weak at the neck and if the skin is subjected to much handling the head frequently becomes detached.

(B) Another method is to prepare the bird and withdraw the stick as described, but at the end to take a thin pointed stick such as a wooden applicator (see appendix 1) and pass it through the cloaca and up through the passage left by the withdrawal of the larger stick in the body until it reaches the skull. The legs can be tied to the lower end of it and the skin allowed to dry in the normal way. There may be difficulties with this method if the cotton wool has expanded sufficiently to close the passage formed by the original stick.

(c) A third method is to begin stuffing by passing a stick through the cloaca and out through the incision, then building up a cotton wool body on the stick. Then ease this body into the tail end of the skin, compressing it until the stick has been pushed back far enough for the tip to slip inside the skin and be pushed up into the skull, the cotton wool body being allowed to expand again as the stick is moved up. In this case a little additional padding may have to be inserted.

\section{SKULl PNEUMATIZATION}

In a very young bird the upper cranium appears to consist of a single, very thin, transparent bony layer. As the bird matures this will change to two layers, separated by minute bars of bone between the two (fig. 19). At this later stage the skull is more opaque. This pneumatization (or ossification as it is sometimes incorrectly called) tends to occur first along the sides and midline of the cranium and in subadult birds the hinder part of the skull will show transparent patches, or "windows", where the separation has not yet formed (fig. 19). In a few species these windows may persist, but in most birds the separation gradually forms, the length of time varying from one species to another. Since the existence of such windows may indicate the age of a specimen, a statement that pneumatization was complete or a small 


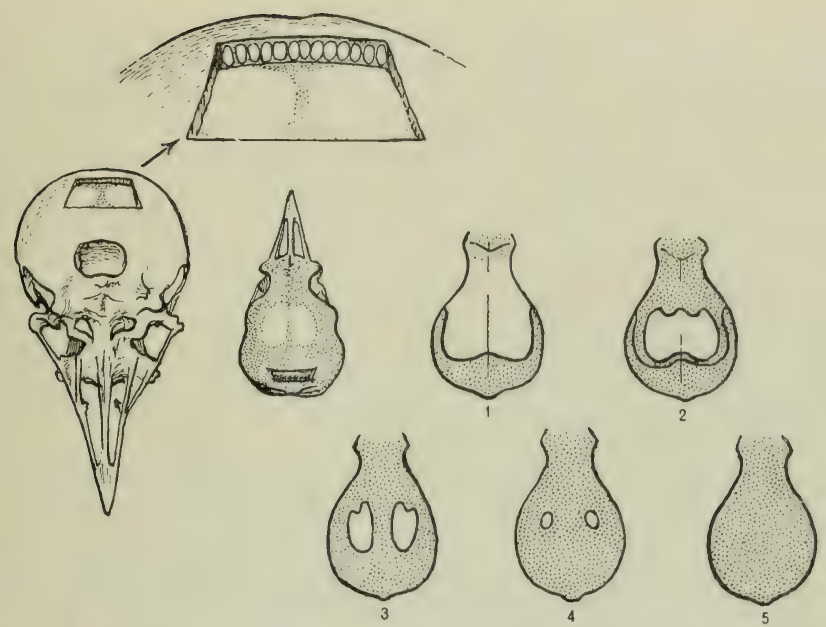

Fig. 19. Pneumatization of the skull. An enlargement of the cut skull shows the appearance of the pneumatized layer. The same skull shown from above (reduced in size) indicates how un-pneumatized areas appear. Diagrams 1-5 show reduction of pneumatization with age.

line diagram of the cranium indicating the shape and extent of any transparent windows should be added to the label and/or data records (fig. 19). Particularly in small birds, where the skull is in any case very thin, it may be difficult to be certain if and where such windows occur. The examination of any cut edges and the inside of the skull with a hand lens may help in determining if any are present. The presence of sutures, lines indicating the separate bones of the cranium, should also be noted. These are present in very young birds and disappear in adults.

\section{SEXING}

If the skinning has been done carefully the carcase that has been removed should consist of the entire undamaged trunk with some limb bones attached. This carcase, particularly in the case of rare species, could provide valuable information on structure, musculature and internal anatomy. Ideally the most satisfactory method is to treat this as though it were a whole specimen and prepare it in a similar manner (p. 33), taking great care to see that it is marked with the same reference number as the skin and that it will be possible to relate skin to carcase. Sex, gut contents, and similar information can then be obtained from the carcase at a later date. If, however, this is not possible and the carcase cannot be fully preserved the following examination should be carried out.

Before the carcase is discarded it should be opened up to determine the sex of the specimen by examining the sexual organs. Do not sex the specimens from the plumage and if it is not possible to examine the sexual organs, merely note this and leave the specimen unsexed. 
Take the skinned body, place the point of the scissors in the vent and cut the wall of the body upwards and diagonally out towards and through the ribs, repeating this on each side, It is now possible to lift up the sternum to expose the intestines and other organs. Push the liver and intestines to one side to expose the kidneys, which are elongated flattened bodies pressed against the inner surface of the pelvis just posterior to the lungs. The sexual organs vary considerably in size according to the season, and in some stages are easily overlooked in favour of the adrenal bodies. It is therefore advisable to identify the adrenal bodies first. These are a pair of small white bodies, slightly triangular rather than round in outline, attached to the more anterior part of the kidneys. They are closely attached to the pelvic wall whereas the sexual organs are attached to membranes in the body cavity near the kidneys, and if the membranes have become damaged they may easily be displaced when the intestines are moved.

The testes, the male gonads, are paired bodies lying, like the adrenal bodies, on either side of the central line. In the breeding season they are large and unmistakable (fig. 20a) but at other times and in immature birds they may be tiny pinhead-sized objects (fig. 20b). They are usually white or creamcoloured but after breeding may appear blackish. They are rounded in appearance and symmetrical. When fully developed one may be larger than the other (the Coucals, Centropus spp., have only the left-hand testis).

The female ovary is usually a single organ on the left-hand side, but care

(a)

(b)
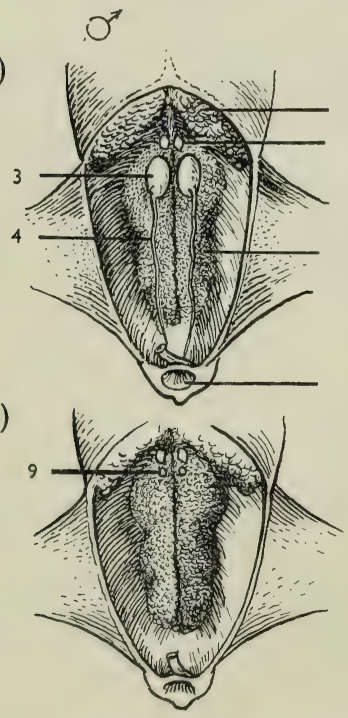

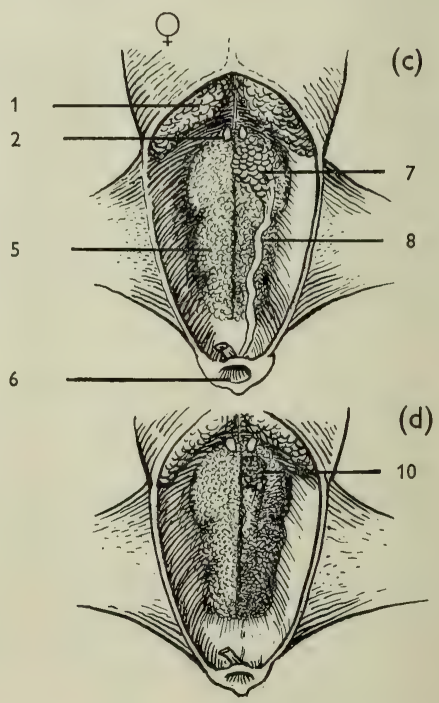

Fig. 20. Dissection of the male (a), female (c) and immature birds (b) and (d), to show position and size of the reproductive organs. 1 , lungs ; 2 , adrenal body ; 3 , testis ; 4 , sperm duct ; 5 , kidney ; 6 , cloaca ; 7 , ovary ; 9 , undeveloped testis ; 10 , undeveloped ovary. 
must be taken with some birds such as the birds of prey in which there may be paired ovaries in the same position as the male testes. The ovary is flattened, elongated, and asymmetrical in shape, and has a granular appearance due to the presence of the oocytes, the rudimentary eggs. In the non-breeding season when the latter are small the ovary may appear as little more than a whitish film (fig. 20d). In the breeding season the granular mass is more obvious (fig. 20c) and may at times be very large and include several incipient egg-yolks. Whereas the testes have thin paired ducts leading to the vent, the ovary has a single, thicker and more obvious oviduct. In immature birds the oviduct is thin and straight but in birds which have bred it is convoluted.

Note the sex on labels and any other data records, the males being indicated by ${ }^{A}$, females by $q$. Where there is any doubt indicate this with a question mark. In addition a small diagram indicating the actual size of the sexual organs, with indications of any developing yolks in breeding females and notes on whether the oviduct was convoluted, and whether any forming egg was present in the oviduct, should also be added.

\section{CROP AND GUT CONTENTS}

It is often difficult to discover the food of a species under natural conditions and a note of the contents of the crop and gut, or the preserved contents of these, may be of considerable value. The collector should remember that it is probably far easier for him to identify food remains, either plant or animal, while on the spot, than it is for someone else to do so not knowing what was present.

Seed-eating birds usually accumulate a large amount of seed in a crop at the base of, or to the side of, the neck, prior to digestion. Since this seed has not reached the digestive juices it is easy to preserve, if so desired, simply by removing the crop with its contents, cutting through the gut above and below it in the case of a large bird and allowing the whole to dry, placing it in a paper bag or envelope before it disintegrates. The gut contents are obtained by opening up the alimentary canal, identifiable remains being found in the upper parts as far down as the stomach and gizzard, but being unlikely to occur in the intestines. The remains are more difficult to preserve and should be put into corked and labelled tubes containing a solution of about 10 percent alcohol. All remains should be carefully labelled with the collector's number for the bird specimen, the name of the species, and its age and sex, the locality and date.

Where the contents are merely noted some effort should be made to be as specific as possible. Merely to put "seed" or "insects" give relatively little information. If possible the size of food particles and the relative proportions of different sizes taken should be indicated. In examining gut contents it should be remembered that in general it is only the relatively hard or indigestible remains that will be identifiable and soft or semi-liquid foods may leave no recognisable remains.

\section{INTERNAL PARASITES}

Parasitic worms occur frequently in the intestines of birds and may also occur in other body tissues. For intestinal worms the easiest collecting method may be to preserve a large portion of the gut in its entirety. If parasites are found elsewhere in the body a portion of the tissue containing 
the parasite should be removed and preserved. The tissues to be kept should be placed in $70 \%$ alcohol, with the volume of liquid at least four times that of the specimen, or in $10 \%$ formalin. Parasitic worms tend to contract or curl when killed and should therefore preferably be killed by immersion in a hot (almost boiling) solution, either water or alcohol. If alcohol is heated great care must be used since the vapour given off is highly inflammable. The danger is less if a deep and not very wide vessel is used. If alcohol is used the specimen should be left in it for twenty-four hours and then transferred to a smaller quantity of fresh alcohol for storage. If water is used the specimen should be transferred immediately after death to a solution of $70 \%$ alcohol or $10 \%$ formalin. The tube or container in which it is placed should have a label written in waterproof ink or pencil giving the collector's number for the host specimen, the name of the host species and its age and sex, the location and date, and the part of the body of the host in which the parasite was found.

Further details are available in a pamphlet publication of the Smithsonian Institution (see appendix 2).

\section{PACKING SKINS FOR STORAGE}

Once skins have dried completely they can be packed more economically by removing the paper tubes in which they were placed for drying, and packing them closely in a strong wood or metal box. This should be lined with polythene or waxed paper to make it as airtight and waterproof as possible. A layer of cotton wool is placed on the bottom of the box and around the sides. The skins are packed side by side and layer upon layer, arranged so that the tails do not point toward the sides of the box. The largest birds must be placed at the bottom and the smallest on the final, top layer. Within each layer the birds are arranged as described below, the first row being arranged along one side with heads towards the side of the box, and subsequent rows arranged with the heads in the same direction, save for the last row which is reversed. As each skin is placed into the box small pieces of cotton wool are packed lightly between the bird and its neighbour, so that any movement is prevented. When the first row is complete a strip of cotton wool is placed along the line of feet covering any sharp claws, and the second row is arranged with the heads slightly overlapping onto the cotton wool strip. This is continued until there is only room for one row, and in this the position of each bird is reversed so that the head is towards the other side of the box, thus preventing damage to the tail if the contents shift. Each layer is covered with cotton wool and newspaper, any unevenness being first levelled out, and any low spots filled in with cotton wool. Subsequent layers are added in similar fashion, care being taken to make each as level as possible and putting layers of paper and cotton wool between each. Throughout the packing process crystals of some insect deterrent such as naphtha or paradichlorbenzene are added in small quantities, care being taken to avoid putting it in direct contact with the plumage. Birds can be packed in this way for transport, but if there is any likelihood that the container might be placed on end, or the wrong way up, care must be taken to ensure that any free space inside the box is completely filled with padding until the whole forms a firm mass that is not likely to move. 


\section{PREPARING SKELETONS}

Specimens intended for skeletons are not completely prepared in the field but only roughed out and dried so that they will reach the museum intact. Special care is needed to ensure that all the skeleton, including the small bones of wings and tail, reach the museum, and that none are lost during field preparation.

\section{PREPARATION}

If the identification of the species is positive, remove the plumage. If the identification is in any way doubtful do not remove any plumage but only eviscerate and sex as described below. Whenever possible refer the specimen, by number, to an identical skin or spirit specimen which was collected at the same time (i.e. "this specimen identical with no. G21"). Unidentified specimens without plumage are useless, while wrongly identified ones may cause serious mistakes and confusion if they are put into collections.

The plumage is best removed with the skin, care being taken to damage no bones. Skin right over the skull and as far as possible down the legs. The eyes, brain, windpipe, and tongue are left in place. Wing and tail feathers are removed by plucking, and here again care is needed to ensure that the small end digits of the wings and of the alula or bastard wing, and the end vertebrae of the tail, are not pulled off. If it is difficult to remove the feathers without risk of damage to the skeleton, the feathers may be clipped off short. After removing the plumage open the body cavity and remove the contents, including heart, lungs, liver, kidneys, and intestines, leaving the body cavity empty, but identifying the sexual organs and sexing the bird during this process (see p. 27). Note the sex and size of organs for labelling. Scissors should not be used during evisceration, nor should any ribs be cut. To assist the drying of larger birds, it is advisable to make several longitudinal cuts with a knife through the breast muscles. With unidentified matcrial the breast plumage should first be deflected to one side by rough skinning and then repositioned after the cuts have been made into the muscle.

\section{DRYING}

The specimen should be made into a compact bundle by gently folding the head and neck forward on the breast, folding legs and wings inwards against the body, and holding the whole in position by binding it round with fine string or thread. The carcase is then hung on a line in a sunny spot until completely dry. In very humid climates some measure of artificial drying may be necessary. It is inadvisable to label the specimen fully at this stage since the labels may become illegible through soiling with blood or fat. All the data should be noted in a field notebook or on data sheets, with a collector's number for each specimen. A relatively indestructible label bearing this number should then be firmly tied to the specimen. The best type has been found to be a thin non-corrosive metal garden label on which the number can be embossed with a pointed, but not sharp, instrument, and which can be attached to the specimen with fine wire or strong thread. Such labels can be cut into smaller tags with scissors for more economic use. 
Alternatively light wooden tags or cardboard labels marked in indian ink or pencil will serve.

Care should be taken to see that the line is hung well out of reach of prowling animals, and where scavenging birds will find it difficult to reach. When in camp it may be advisable to take the line in each night and to put it in a box until morning to avoid loss of specimens to agile nocturnal animals. No chemical preservatives should be used in or on these specimens (other than those suggested later) since the final preparation may involve using insects to clean the bones, and the presence of persistent chemicals in the dry flesh would make this impossible.

\section{WRAPPING}

When the specimens are completely dry and the meat is quite hard they can be taken down and wrapped. They can conveniently be labelled at this period (see p. 39). They should be individually wrapped in newspaper which is then secured with a pin or binding. At this stage a few grains of an insect deterrent that will evaporate, can be washed off, and will not penetrate the flesh, should be put with each specimen. Paradichlorbenzene crystals or naphtha ("mothballs") may be used, but not DDT compounds. It is most important that the specimens should be fully dried. In very wet conditions where this is not possible the specimen should be wrapped when as dry as possible and subsequently aired for further drying on all possible occasions. The wrapping need not be removed. Never place specimens in polythene bags.

\section{StORAGE}

The skeletons can be packed in their individual wrappings. Each should be examined to ensure that the wrapping is sufficient to prevent any bone which might become detached from being separated from the body. They should be closely packed in a container with a little padding where necessary, so that they fill the space and will not move. The container should preferably be airtight; a metal container with a close-fitting lid being best, and a suitable chemical insect deterrent (see above) should be sprinkled among them as they are packed. They should never be packed in the same container with skins. 


\section{PREPARING WHOLE SPECIMENS}

Whole specimens, like skeletons, are easy to prepare, but are a little more difficult to preserve than either skins or skeletons. After collection they must be either kept in a solution or packed in such a way that they remain moist, and they therefore tend to be both bulky and heavy. The liquids in which they may be kept are of two different types, one being based on alcohol, the other on formalin. Alcohol may be easier to obtain (if only in its more drinkable form) in most parts of the world, but there may be local regulations regarding its purchase and transport. It is very volatile and inflammable. Formalin solutions have the advantage of being more inert, and can be carried in a more concentrated form, but are less easily obtained, corrode many metal containers, and produce unpleasant fumes.

In the field the formalin method may be easier in that it involves only a single solution, but this should not be put in a metal container and a glass or plastic container with a top that can be fixed tightly in place is needed. Alcohol prevents the decay of flesh but also gradually removes the water from it and unless additional treatment is given may cause specimens to shrink and harden over a period of time. It is necessary to inject a weak formalin solution into specimens to "fix" the tissues before they are immersed in alcohol, and for the proper treatment of alcohol specimens one will require two bottles containing fixing solutions, plus a container with weak alcohol in which specimens can remain for two or three days, plus a container with a stronger alcohol solution for final preservation.

In all cases a hypodermic syringe will be needed for injecting the specimens. The best type for field use is one made of plastic rather than glass. The needles are usually supplied with a fine wire for keeping the bore clear and a watch should be kept during the injection of a specimen, since a number of injections are needed for each bird and the needle may easily become blocked with tissue. If this happens some parts may not receive the preserving fluid and may subsequently deteriorate.

\section{PREPARATION OF SPECIMENS}

1. In alcohol. For this a solution of $10 \%$ formalin (see appendix 1), and a solution of $75 \%$ glycerine and water are required for injection, together with a weak solution of $10 \%$ alcohol in a container in which the specimens can be immersed (see appendix 1 for preparation of solutions). The specimen is injected as soon as possible after collection. A hypodermic syringe is filled with the formalin solution. Injections are made into the muscles of the breast, legs, wings, and in large birds the muscles of the back as well. The needles should be thrust well into the muscles and then drawn slightly back, and the part being injected should be held lightly between the fingers. As the plunger of the syringe is pressed down a slight distension of the muscle can be felt as the fluid is injected. This enables the collector to check that injection is occurring. Injections are also made into the abdominal cavity via the belly, and into the thoracic cavity at the base of the neck in front. A small injection is also made into the skull by pushing the needle up through the roof of the mouth, from outside and below.

The specimen is then left for ten minutes for the formalin to spread into 
the tissues. A syringe is now filled with the glycerine solution. This is a thick heavy solution that is not easily drawn up by the syringe and it may be easier to withdraw the plunger and fill the barrel up by pouring the solution in. Injection is also a little slower and a larger-bored needle is needed. The specimen is injected with glycerine with the same routine as before, and left for a few minutes. It is now ready for immersion, and should bear an inscribed tag or label, firmly knotted onto the leg, and with the information written in pencil (see information on labelling, p. 39).

The specimen is now completely immersed in $10 \%$ alcohol solution. After two or three days the specimens should be transferred into a solution of $75 \%$ alcohol. During the preparation period the weak solution of alcohol should be topped up with additional spirit from time to time to maintain its strength, and the $75 \%$ solution will also require additional alcohol at intervals as it takes up moisture from the specimens.

2. In formalin. If the necessary additional chemicals are not available a solution of $5 \%$ formalin (see appendix 1 ) with two tablespoonsful of common salt per quart added to counteract the hardening action can be used for preserving specimens. If possible a Kaiserling no. 1 solution (see appendix 1) should be prepared for the purpose. The specimens are injected with this solution with the same routine of injection as described above for alcohol specimens, the difference being that only the one solution is used and the specimens are immersed in the same solution.

\section{PACKING WHOLE SPECIMENS FOR STORAGE}

Although whole specimens may be left immersed for any length of time in the preserving fluids it is usually inconvenient to transport them to the museum in this manner. Once they have been well soaked and permeated with the fluid they may be removed, wrapped with a layer of cotton wool or cloth soaked in the preserving fluid, care being taken to pad the bill and claws, and then placed in a polythene bag. The bag is squeezed shut, as much air as possible being excluded, and it is then either sealed by heating or tied tightly with string in a double tie. The specimen is now a small padded package from which moisture is unlikely to escape, and numbers of these may be packed into boxes or, better still, into metal containers with closefitting lids. In the latter they will store and travel safely for indefinite periods. 


\section{COLLECTING EGGS}

There is less reason for collecting eggs now than there was in the past, unless the collector is in a region in which the nidification of many species is unknown. When eggs are taken the collector must make sure that he has correctly identified the nesting bird. Serious errors have been caused through collectors assuming that a bird near a nest must be the owner of it. It may be necessary to collect the bird on the nest to be certain of identity.

\section{Preservation OF EGgS}

The only part of the egg which is usually preserved for collections is the shell. This is saved by removal of the contents, preferably when the egg is freshly laid. The contents are removed through a hole in one side (not in the end) opposite the side which it is considered most desirable to show, so that the egg can be exhibited with the hole concealed beneath it. A neat hole can be made with a drill, and small conical drills which could be used to produce holes of varying size were available in the past but are now more difficult to obtain. The larger sizes of drills used in dentistry can be employed for this purpose. If nothing else is available a small hole may be chipped in the side of the egg with a suitable sharp pointed instrument. The hole should be large enough for the contents to nass out leaving the eggshell clean. In small eggs the hole might be c. 1-2 mm. in diameter, and in larger eggs c. 3-5 mm. There has been a tendency for collectors to blow an egg through the smallest possible hole, but for scientific purposes it is better to make a larger hole and ensure that the shell is properly clean than to make a tiny hole through which the contents will not completely pass.

The contents of the shell are blown out through the hole with a blowpipe, the tip of which is inserted into one side of the hole. The blowpipe is a small tube, and it is most convenient to have one which tapers and curves upwards towards the end. It may be of metal but can easily be made by drawing out and bending the end of a glass or plastic tube. In the field, if nothing else is available a hollow grass-stem may be used. The egg is held hole-downwards, preferably over a bowl half-full of water to make subsequent disposal of contents easier. The tip of the blowpipe is inserted into the hole, and by blowing firmly into the other end, and by moving the tip slightly and adjusting the pressure of air used, it should be possible to blow out the contents of the egg. It may be necessary to prick the yolk with a needle to make it run more easily.

Clean water is then drawn into the egg either by filling the blowpipe with water and blowing it in, or by immersing the egg, hole uppermost, and drawing out the air with a blowpipe. The water is then blown out to rinse the shell. This can be repeated if necessary. The shell is placed on some absorbent material, hole downwards, to dry, being moved from time to time and inspected. A watch should be kept for traces of yolk on the outside of the shell which, if not wiped away while liquid, will cause the shell to adhere to other objects as it dries. Once it is dry, data can be entered on the shell (see section on labelling, p. 39). At all stages the empty eggshell is very fragile and must be handled with great care.

If the contents of the egg are rotten great care should be taken in drilling 
the shell and, where possible, it will be found desirable to blow the egg while holding it in a stream of running water under a tap. In some species the surface pigment of the shell may be smeared by handling when it is freshly laid, and where there is evidence of this great care must be taken in handling and cleaning the shell. Incubated eggs are difficult to deal with. If the formed embryo is small it may be possible to destroy it and remove it through the hole with a curved needle or small wire hook. With embryos too large and solid for these, elaborate methods have been advocated, but if the shell is needed the simplest way is to try and break the shell into two as neatly as possible, and then carefully preserve the two halves.

In cases where the eggs contain embryos in a very advanced stage of development these may be more important than the shell. To preserve them a portion of the shell should be removed, and a preserving fluid such as is used for preserving whole specimens should be injected into the egg, care being taken to pierce the membranes surrounding the embryo. The whole egg can then be immersed and treated like a whole specimen (p. 33), the data being noted in pencil or indian ink on the shell instead of a label.

\section{PACKING EGgS}

Eggshells are extremely fragile. They should be wrapped individually in cotton wool and then placed in a container in which all the free space has been filled with soft padding so that the eggs will not move. The container should be sufficiently rigid to withstand pressure, since both pressure passed to the eggs through the packing, and sudden jolting of insufficiently padded eggs, may break them. 


\section{COLLECTING NESTS}

Where it is possible to collect and preserve the nest it is useful to do so since the nest may provide additional information on the species and its affinities and the nests of exotic species are less well known than their eggs. It is usually fairly easy to collect and preserve small nests of reasonably compact structure, but this may be out of the question with others of loose structure or large size.

In every case notes on the position, construction, and shape of the nest, together with information on the materials used, and if possible a sketch or photograph, should be made. Where possible, the nest should be collected together with the support to which it was attached or upon which it was built so the parts of it are not disarranged or destroyed. The actual mode of attachment may be an important feature. Polythene bags are convenient for nest collection since all the material can be kept together, but care is needed during transport to ensure that they are not crushed. As with eggs the collector must be sure that he has correctly identified the bird that is using the nest.

In the case of ducks and geese, samples of the down with which the nesthollow is lined may be collected.

\section{COLlECTING NEST PARASITES}

Nests are often the refuge of a large number of bird parasites, particularly fleas. These can be collected by methods similar to those used for collecting external parasites from dead birds (p.9). As with dead birds it is advisable that nests from which material of this kind is to be collected should be kept separate from one another to avoid transference of parasites. If the nest is put into a white bowl it will be possible to see and collect any insects that leave it. The nest may be left in a cool dark container and examined at intervals of several days for emerging parasites, or, if it is not required, may be teased apart for parasites. For nests that are to be retained it is best, if they are small enough, to treat them like bird bodies by putting them into an air-tight container with cotton wool soaked in chloroform and then picking up the parasites that fall out. These parasites should be preserved in the manner described on page 10 .

\section{PRESERVATION AND PACKING OF NESTS}

The nest should be properly labelled (see section on labelling, p. 39). The label should be firmly tied to the nest itself, being sewn to the structure. In addition to possible treatment to collect parasites (see above) it should be well-fumigated with insecticide, and a suitable deterrent should be put into the container in which it is kept. The insect population of nests usually includes moths and their larvae which, if allowed, will ultimately destroy parts of the nest. Similar treatment is also needed for down from the nests of ducks and geese since moths are often present which may destroy this entirely.

The nest cavity should be padded with cotton wool or similar material so 
that the shape and arrangement of nest material is retained. This is especially important with thin-walled, fiimsy nests. The nest should be put in a box or container large enough to take it without flattening or distorting it. Thickly woven nests such as those of weaver birds can stand a certain amount of compression without harm, but with other nests this may destroy the structure. A number of nests may be packed into the same container, but they should be individually wrapped so that material from one does not become detached and adhere to another.

There is no good way to preserve the larger and looser nests. Attempts have been made to spray these with plastic resins to create a more solid moveable structure, but the effort involved is likely to be considerably greater than the scientific value of the end-product. 


\section{RECORDING INFORMATION AND LABELLING}

The importance of recording information and labelling the specimen cannot be over-emphasized. However well the collector has done his work a specimen without data may be almost useless for bird study and the time and effort expended in collecting it will have been largely wasted. The more complete the data the more valuable the specimens. This part of the process should therefore be regarded as equal in importance to the actual collecting and preparing of the specimen. The information collected and noted will be similar for all types of material, but the way in which they are labelled will differ according to the nature of the material.

\section{THE INFORMATION RECORDED}

Theoretically the amount of information that can be noted for any particular specimen is only limited by the time and space available for it. In practice we recognise that this information varies in importance, some facts being less essential than others, and we can subdivide it into three categories.

1. Essential information. This information that must be entered on the specimen label. It includes:

(a) The collector's number for that particular specimen and the collector's name (this will link the specimen with information recorded elsewhere).

(b) The date and time of collection. The date should be written in the sequence day-month-year, and the month always written in letters, not figures, to avoid possible confusion.

(c) The locality, including the actual place where the bird was collected, the division, county or state, and the country. If the locality is relatively unknown the distance and direction from the nearest settlement likely to be found on most maps should also be indicated. If possible the approximate latitude and longitude should be given, and also some indication of height above sea level, especially among mountains or in areas where there are marked altitudinal changes in vegetation.

(d) The name of the species, if known (this may be left blank and filled in after subsequent identification at the museum).

(e) The sex of the bird as determined by dissection, the diagrams of the sexual organs, and any information as to age (if known).

2. Further important information. This is additional basic information on the specimen. It includes:

(a) The degree of pneumatization of the skull.

(b) The colours of legs, eyes, bill, mouth, and any other bare skin, all noted when the bird was first killed.

(c) The weight, preferably in grams, if recorded (this should also be done when the bird is first killed).

(d) The habitat, with an indication of the particular part apparently occupied by the bird, i.e. whether in low cover, or on bare branches, or feeding in foliage canopy, etc.

3. Additional information. This type of information is useful but may or may not be included with the specimen on labels. It includes: 
(a) Gut and crop contents.

(b) Behaviour as observed prior to collection.

(c) Evidence of moult, if any.

\section{RECORDING INFORMATION}

The information in the first category must always be entered on the specimen label, but that in the third category and some from the second category is often entered, with other field data on the species, in a separate field notebook or on special data sheets. This method has the disadvantage that over a period of time the labelled specimens and the field notebooks tend to become separated and the latter may be lost. Unless a definite collection is being made over a limited period and great care is taken to ensure that the field data will accompany the specimen to the museum immediately it is finished, it is better to use two labels for a single specimen and so ensure that all the necessary data accompany the specimen itself. With skeletons and whole specimens however the treatment for preservation and the subsequent storage may mean that labels become damaged or illegible, and in the case of such material it is best to duplicate the information on labels and in field notebooks or on data sheets, and if circumstances allow the data for skins should be duplicated in a similar manner. Where a journal or field notebook or data sheet is used the collector's number must be used when referring to an individual bird to ensure that the information can be related to the right specimen.

\section{LABELLING}

A standard museum label should be used where possible. Labels should be made out and attached to specimens at the earliest possible opportunity to avoid the accidental separation of specimens from the relevant data. When writing the label have the threaded side always to the left so that both sides can be examined with equal ease. Usually the essential, first category, information is entered on one side and the additional, second category, information on the other. Where several specimens, such as a bird together with its nest and eggs, are taken simultaneously, the label of each should have a reference to the others and the collector's number by which they can be located.

1. Labelling skins. If labels are not available they can be cut, about $1 \times 3$ ins. in size, from durable white paper, which should be fairly waterresistant and capable of taking ink. One or two holes are punched in one end about $\frac{1}{4}$ in. from the edge and a strong thread passed through with which to tie it. The label should be tied to the legs of the specimen with a firm knot that will not slip and with about an inch of thread between the bird and the label so that the latter can be easily examined. The information should be entered in waterproof ink or pencil, never in indelible pencil or ball-point pen.

2. Labelling skeletons. Skeletal specimens are labelled in a similar manner to skins, but, as described in the text on preparation (p. 31), a numbered tag is used until the specimen has been properly dried, when it can be labelled before it is wrapped. The numbered tag should be left on, and the 
label tied firmly to a leg of the specimen. A duplicate record of the data should be kept.

3. Labelling whole specimens. The labelling is again similar but the labels of whole specimens will be immersed in liquid. Special "wet labels" are used by most museums. If labels have to be prepared from material to hand, care should be taken to use strong paper which is not easily reduced to pulp in liquids. Paper incorporating linen fibres, or with a plastic finish would be suitable. Metal tags must not be used since these corrode, and in formalin solutions the metal eyelets on manufactured labels will deteriorate. The label should be printed clearly in pencil or indian ink. If the latter is used care must be taken to see that the ink is quite dry and the label should then be soaked in water before being tied on and immersed in the preserving solution. Labels must be tied to the leg of the specimen with a tight reef knot. As with skeletons it is advisable to keep an additional duplicate record of the data elsewhere.

4. Labelling eggs. Data can be written on the shell itself with a fine pencil or indian ink, as soon as the shell is dry. The information is usually inscribed around the hole made for blowing out the contents, the writing being as small as possible. A serial number is assigned to each clutch and written on each egg. The amount of additional writing on the shell will depend on its size and the skill of the collector. The name of the bird, possibly in abbreviated form, the locality, date, collector's initials and the number of eggs in the clutch expressed as $c / 2$ or $c / 3$ etc., may at all times be entered on the shell. In addition all this information, together with data on the nest and habitat, is entered on a data slip or label which is kept with the clutch. The information given should be as precise and extensive as that accompanying any other specimen.

5. Labelling nests. Nests are labelled in a similar fashion to skins. The label should be firmly tied to the nest itself. The thread or thin string of the label can be threaded through a large darning needle, and passed through part of the nest wall and tied, to ensure that it is properly attached. 


\section{TRANSPORT}

Specimens packed for transport must be in rigid containers such as wooden or metal boxes which are able to withstand jarring and pressure. These should be clearly labelled with an indication of the contents which should be described as "Natural History specimens for scientific purposes only; no commercial value". Birds collected for scientific study and sent abroad may be cleared for export very readily when local regulations have been met. Such regulations will differ from one country to another and the collector should make certain what the requirements will be well beforehand, since some authorities may require detailed lists of specimens and localities. Where lists are prepared it is useful to have a number of copies, since apart from other authorities both the collector and the recipient of the specimens will need one.

Specimens sent to the British Museum (Natural History) should be addressed as follows:

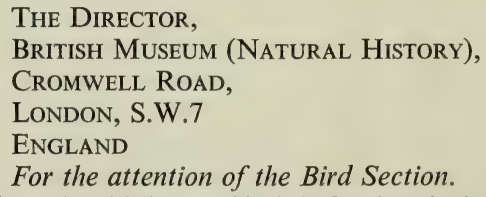

THE DiRECTOR,

British Museum (Natural History),

CROMWELl ROAD,

LONDON, S.W.7

ENGLAND

For the attention of the Bird Section.

The Bird Section should be notified beforehand that these are being dispatched. 


\section{APPENDJX 1}

\section{CHEMICALS AND MATERIALS}

PENTOBARBITONE SODIUM SOLUTION. Used in the strength as commercially supplied. This is very potent and a few millilitres will kill a large bird rapidly and painlessly.

DUSTING POWDER. This is a mixture of potato flour and magnesium carbonate in equal quantities of each by volume. If it is not possible to obtain both, either may be used alone. "Instant" potato powder sold commercially for food is satisfactory. If these are not available powdered cornmeal may be used, or even fine sawdust or dry sand, although the latter two are not as effective in absorbing fat or moisture.

POWDERED ALUM. This absorbs moisture rapidly and is useful for drying out small pieces of flesh and tissue which are not easy to remove. It should be used sparingly and when possible scraped away after use. It must not be used on the insides of skins as a preserving agent since it will cause them to fall apart at a later date. Because of its tendency to absorb water it should be kept in an airtight container.

\section{PRESERVATIVES FOR USE ON SKINS}

1. Arsenical soap. This is extremely poisonous, but although it difficult to obtain than other preparations because of the arsenic content, has the advantage of keeping the skin a little supple and preventing attacks by insects. It can be made as follows:

Ingredients

White bar soap 2 lbs.

Powdered white arsenic (arsenious oxide) 2 lbs.

Camphor 5 oz.

Potassium bicarbonate $6 \mathrm{oz}$.

Alcohol 8 oz.

Soap should be of the best quality laundry soap and of such composition that it can be reduced with water to any degree of thinness. Soap which becomes like jelly when melted will not answer the purpose and should not be used.

Dissolve the camphor in alcohol. Slice the soap and melt in a small quantity of water over a slow fire stirring sufficiently to prevent burning. When the soap is melted add the potassium carbonate and stir in the powdered arsenic. Next add the camphor and alcohol. Stir the mass thoroughly and boil it down to the consistency of thick molasses and then pour into containers and allow to set. To use it mix a small quantity with water until it forms a thin creamy paste and apply with a brush.

2. Borax. This is used as a fine powder applied to the inside of the skin. It is effective in helping to preserve the skin by aiding the drying process but is less effective at preventing insect attack. If used it should be applied liberally.

ALCOHOL. This is available in various forms. Ethyl Alcohol (Ethanol), when diluted with water to a concentration of about $70 \%$ by volume can be used as a preservative, but in many countries is very expensive; and Ethanol 
in the form of a non-mineralized methylated spirit can be used as an alternative. Two types of methylated spirit are usually available-

(a) mineralized and (b) non-mineralized. Only the non-mineralized is suitable for preserving purposes.

(a) Mineralized Methylated Spirit, which often contains a purple or red dye and small quantities of pyridine, is a mixture of ethyl alcohol of a high strength and crude methyl alcohol (wood naptha), with mineral oil added. This is almost useless for preserving animals as it cannot be diluted with water without forming a milky emulsion.

(b) Industrial Methylated Spirit (I.M.S.), also called Ethanol Mixture, or Rectified Spirit, is a non-mineralized methylated spirit containing $92-95 \%$ alcohol by volume and about 5 parts of either crude or pure methyl alcohol. This is sold by some retail chemists and all methylators for manufacturing purposes. It is marked on containers as between 62 and 66 Over Proof. There are restrictions in some countries which govern the sale of this grade of spirit, and the collector may have to consult the Customs and Excise department of the country concerned for permission to purchase, or the local museum or hospital for information.

Collectors need not assess the strength of the alcohol used with fine accuracy but they should ensure that for long-term storage the percentage of alcohol should never fall below $50 \%$.

Alcohol strength can be tested with an alcoholometer of the type calibrated to measure the percentage of alcohol, or with a Sykes' alcoholometer which shows the degrees above or below Proof. With the latter spirit should not be used if the alcoholometer floats at under the Proof mark. British Proof is about $50 \%$ alcohol by weight or $57 \%$ by volume. (Spirit must be over Proof. I.M.S. is about 64 over Proof and contains $95 \%$ alcohol.) For very accurate readings the alcoholometer should be corrected from a table to allow for the varying temperature above or below $60^{\circ} \mathrm{F}\left(15 \cdot 5^{\circ} \mathrm{C}\right)$; but for temporary bird storage in the field, direct readings are close enough.

Spirit can be diluted with water to a weaker grade, either by weight or by volume. For dilution by volume of alcohol to a weaker grade for rough field work, $95 \%$ can be taken as $100 \%$ alcohol for these purposes and diluted as follows.

To make $80 \%$ alcohol add 4 parts alcohol to 1 part water by volume.

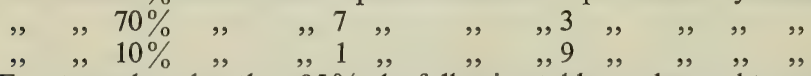

For strengths other than $95 \%$, the following table can be used to estimate the amount of water required to reduce 100 volumes of alcohol of a known percentage by volume.

\begin{tabular}{c|rrrr}
\multirow{2}{*}{$\begin{array}{c}\text { Weaker grade } \\
\text { required }\end{array}$} & \multicolumn{4}{|c}{ ORIGINAL GRADE } \\
\cline { 2 - 5 } & \multicolumn{1}{|c}{90} & \multicolumn{1}{c}{85} & 80 & $75 \%$ \\
\hline $85 \%$ & 6.6 & - & - & - \\
$80 \%$ & 13.8 & 6.8 & - & - \\
$75 \%$ & 21.9 & 14.5 & 7.2 & - \\
$70 \%$ & 31.1 & 23.1 & 15.4 & 7.6 \\
$10 \%$ & 804.5 & 753.7 & 703.9 & 652.2
\end{tabular}


For dilution by weight of an alcohol of known percentage the following calculation may be used.-If $\mathrm{A}$ is the percentage by weight of the alcohol to be diluted and $\mathrm{B}$ the percentage of alcohol required in the new mixture ; to obtain the desired result add A minus B parts by weight of water to B parts by weight of alcohol.

E.g. to make $50 \%$ alcohol from $95 \%$ alcohol add $45(=95-50)$ grammes of water to each 50 grammes of $95 \%$ alcohol.

To make $40 \%$ alcohol from $70 \%$ alcohol add 30 grammes of water to 40 grammes of $70 \%$ alcohol.

Large or small quantities can be made by using different units of measurement. The rule given here is correct for dealing with quantities and percentages measured by weight, but not for percentages measured by volume.

FORMALIN. Commercial formalin is a solution containing $40 \%$ formaldehyde gas in water. " $5 \%$ solution of formalin" means five parts of commercial formalin to 95 parts of water, this strength containing $2 \%$ formaldehyde. For diluting:

$25 \%$ formalin $=10 \%$ formaldehyde $=1$ part commercial formalin to 3 parts water by volume.

$12 \frac{1}{2} \%$ formalin $=5 \%$ formaldehyde $=1$ part commercial formalin to 7 parts water by volume.

$10 \%$ formalin $=4 \%$ formaldehyde $=1$ part commercial formalin to 9 parts water by volume.

$5 \%$ formalin $=2 \%$ formaldehyde $=1$ part commercial formalin to 19 parts water by volume.

$2 \frac{1}{2} \%$ formalin $=1 \%$ formaldehyde $=1$ part commercial formalin to 39 parts water by volume.

FORMALIN AND SALT SOLUTION. 5\% formalin solution with two tablespoonsful of common salt added to each quart of the solution to reduce the hardening action of formalin on the tissues.

\section{KAISERLING NO. 1 SOLUTION.}

Commercial Formalin (40\% formaldehyde) $400 \mathrm{cc}$.

Potassium Acetate $42 \cdot 5$ gms.

Potassium Nitrate $22 \cdot 5 \mathrm{gms}$.

Water $1,600 \mathrm{cc}$.

This will make up about two litres of the solution. In preparing the solution the potassium acetate and potassium nitrate, which are in the form of crystalline powders, should be mixed with a little of the water, warmed until they dissolve, before being added to the main solution.

GLYCERINE SOLUTION. The $75 \%$ glycerine solution consists of three parts of glycerine to one part water.

NAPHTHALENE AND PARADICHLORBENZENE. These are both insect deterrents, obtainable as solids that volatilise slowly. Naphthalene can be bought as solid lumps (including moth balls) or fine flakes of varying size; and Paradichlorbenzene as solid blocks (sold as "air freshener") or as crystals. When not in use they should be kept wrapped and sealed or in an airtight box. 
STICKS. For large birds split bamboo canes are very useful. These can be purchased in bundles from most gardening shops. For small passerine birds the small round wooden sticks called "wooden applicators" and sold for medical use in boxes containing about 72 dozen for a few shillings, are well worth having. 


\section{APPENDIX 2 \\ RECOMMENDED PUBLICATIONS}

Hebditch, J. R. Binoculars and telescopes for field work. New revision 1965. B.T.O. Field Guide number 2.

Hollom, P. A. D., \& Brownlow, H. G. Trapping methods for bird ringers. Revised edition 1955. B.T.O. Field Guide number 1.

Low, S. H. Ringing with mist nets. 1957. B.T.O. Field Guide number 4. The above may be obtained from:

The British Trust for Ornithology, Beech Grove,

Tring,

Hertfordshire,

England.

Hutson, H. P. W. The Ornithologists' guide. B.O.U. 1950.

Obtainable from:

The British Ornithologists' Union, c/o Bird Section,

British Museum (Natural History), Cromwell Road, S.W.7.

Watson, G. E., \& Amerson, A. B. Jr. Instructions for collecting bird parasites. 1967. Information leaflet 477, Smithsonian Institution.

Obtainable from:

The Smithsonian Institution,

Museum of Natural History,

Washington, D.C.,

U.S.A. 


\section{ACKNOWLEDGEMENTS}

We should like to thank the Field Museum of Natural History, Chicago, U.S.A., for permission to base some of our illustrations on those of its similar publication; and we are grateful to our colleagues of the Bird Section and other sections of the British Museum (Natural History) who have assisted us by providing information. 


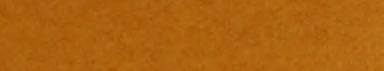

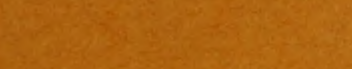

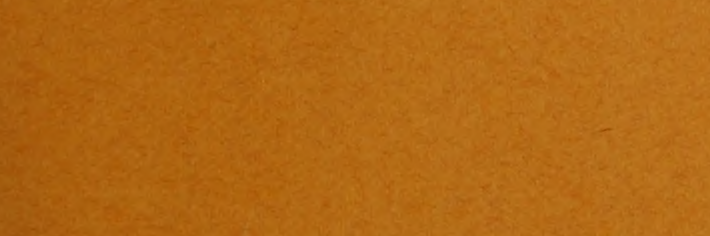

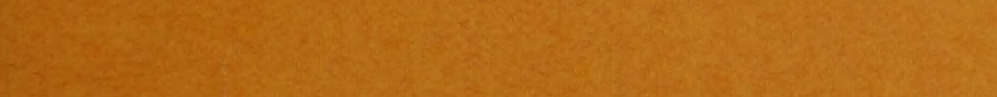
200 -

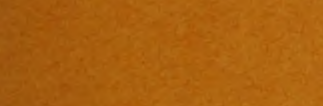

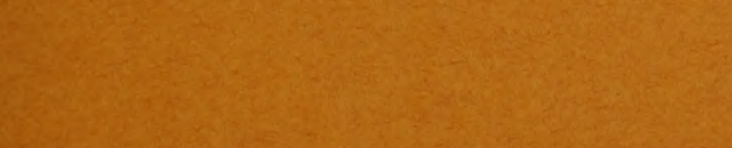

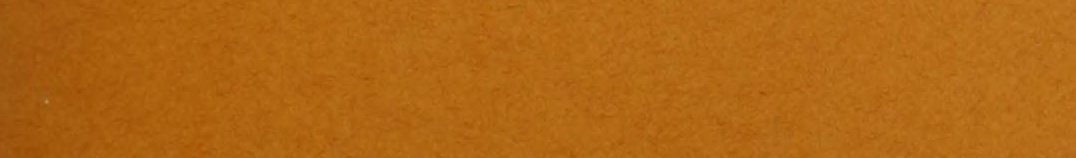

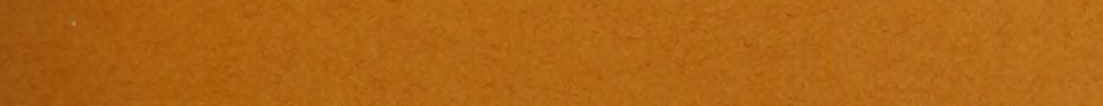

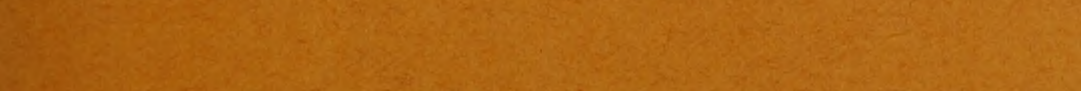
3.

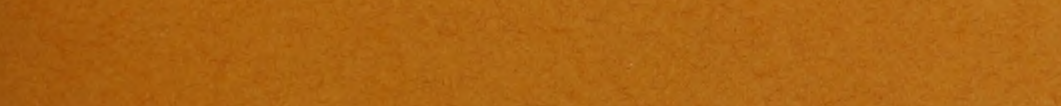

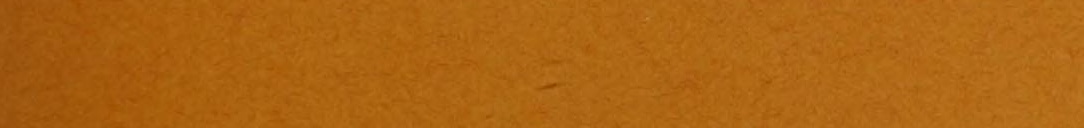

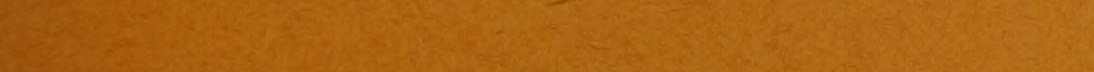
Q4. 40 s.

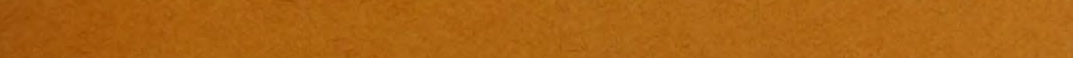

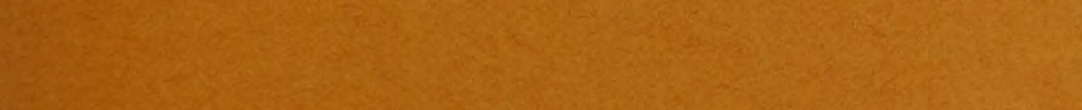

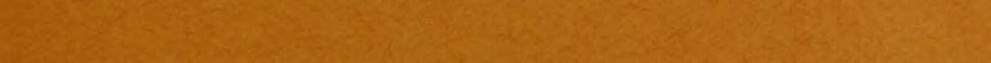

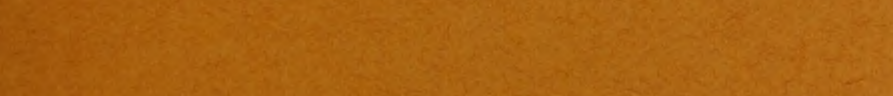
H.

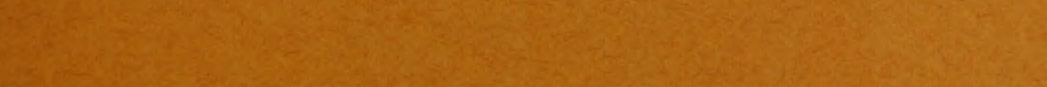

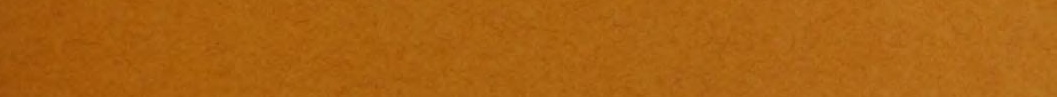
We

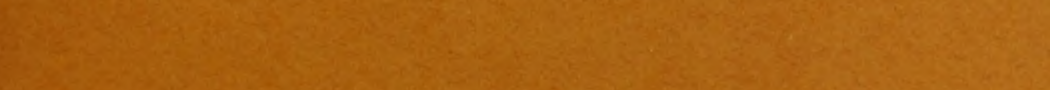
S. What

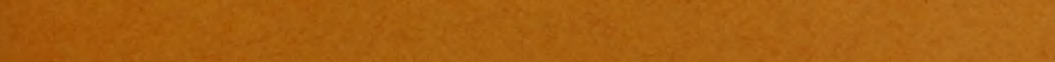

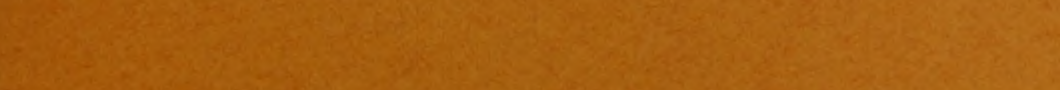
mits

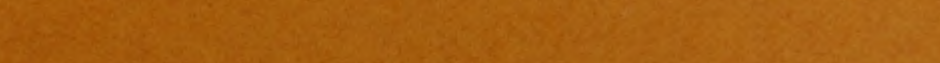


